ECPS Organisation Profile Sejies

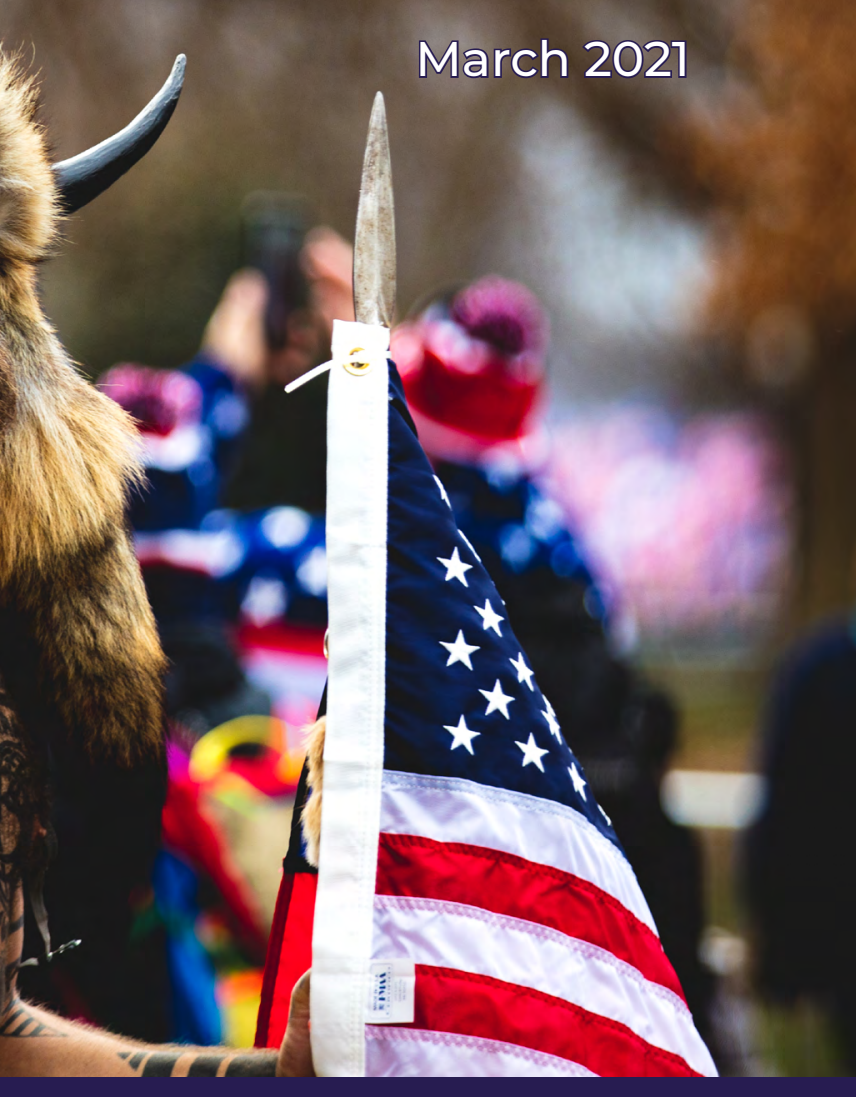

AUTHOR: Bulent Kenes

\title{
QAnon: \\ A Conspiracy Cult \\ or Quasi-Religion of \\ Modern Times?
}

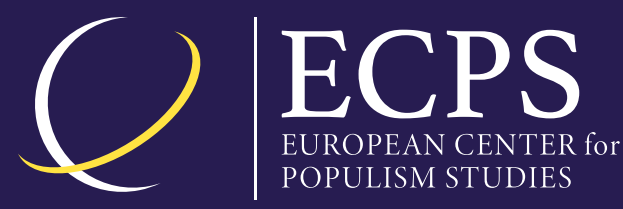




\section{QAnon: A Conspiracy Cult or Quasi-Religion of Modern Times?}

\section{BY BULENT KENES}

\section{ABSTRACT}

As with ISIL, QAnon's ideology proliferates through easily-shareable digital content espousing grievances and injustices by "evil oppressors." To perhaps a greater degree than any comparable movement, QAnon is a product of the social media era which created a perfect storm for it to spread. It was QAnon's spread onto the mainstream social media platforms-and from there onto the streets-that made this phenomenon into a global concern. Social media platforms, again, aided and abetted QAnon growth by driving vulnerable audiences to their content.

BULENT KENES is an academic and a journalist who has over 25 years of professional experience. He has managed multiple publications, both in Turkish and English.

ECPS Leader Profile Series offer analyses of political leaders and prominent public figures with populist tendencies. Unless otherwise indicated, the views expressed by the author are only attributable him and not to any institution with which they are associated.

The profile available for free downloading from the ECPS website (wwW. populismstudies.org)

(C)ECPS 2021 


\section{Table of contents}

1. INTRODUCTION.

2. QANON AS BOTH FERTILE MOTHER AND BRAINCHILD OF CONSPIRACY THEORIES

3. WHAT DOES " $Q$ " STAND FOR, OR, WHO IS " $Q$ " $? \ldots \ldots \ldots \ldots \ldots 11$

4. WHO ARE QANON ADHERENTS? $\ldots \ldots \ldots \ldots \ldots \ldots \ldots \ldots \ldots \ldots$

5. WOMEN OF THE MOVEMENT: PASTEL QANON

6. PANDEMIC ACCELERATES AND WIDENS QANON'S REACH .16

7. QANON'S TIES WITH TRUMP AS CONSPIRACIST-IN-CHIEF .18

8. GLOBAL QANON AS AN AMERICAN EXPORT

9. QANON: ONE OF THE EVIL PRODUCTS OF SOCIAL MEDIA

10. QANON IS INHERENTLY ANTI-SEMITIC 


\section{INTRODUCTION}

The US was shocked by images of a man in a horned headdress roaming the US Capitol during the January 6, 2021 insurrection. These frightening images feature the "QAnon Shaman"-or "Q Shaman"-the online persona of Jacob Anthony Chansley, from Arizona (he also goes by Jake Angeli). Chansley is a known super spreader of conspiracy theories (Tollefson, 2021; Giannotta, 2021). Both on the Mall and inside the Capitol, countless signs and banners were seen promoting QAnon, whose acolytes believe that former US President Donald Trump has been working to dismantle an occult society of cannibalistic paedophiles. At the base of the Washington Monument, Chansley was seen assuring people, "We got 'em right where we want 'em! We got 'em by the balls, baby, and we're not lettin' go!" (Mogelson, 2021).

Many of the January 6 rioters subscribed to QAnon (Jankowicz, 2021), which is an umbrella term for a baroque set of (Bracewell, 2021) eclectic super-conspiracy theories essentially rooted in populism (Smedt \& Rupar, 2020). The QAnon movement emerged from the primordial swamp of the internet on the message board 4chan in October 2017 and has aimed to trigger the resentments of the "everyman." Its series of confusing claims resemble the conspiracy legends of the past, but the power of online social media has given platforms to members of "Q" to share, promote, and connect (Smedt \& Rupar, 2020; Wong 2020).

QAnon alleges without evidence that the world is controlled by a secret cabal of Satan-worshipping paedophiles who are abducting, abusing, and ritualistically murdering children by the thousands. This global child trafficking ring counts among its members powerful elites like Pope Francis and Ellen DeGeneres, as well as many prominent members of the Democratic Party like Hillary Clinton and Barack Obama. Trump also plays a leading role in the QAnon mythos as a secret-agent/warrior/messiah figure. Recruited by top military generals to run for president in 2016, Trump has been working tirelessly behind the scenes ever since to defeat this Satanist cabal. What gives the QAnon movement its unmistakable populist tinge is the role it proscribes for its supporters in the apocalyptic confrontation between Trump and the paedophilic cabal (Bracewell, 2021). QAnon supporters believed, in the leadup to the 2020 election, that there would soon be mass arrests, and members of the cabal would be brought to justice (Beckett, 2020).

The QAnon narrative includes centuries-old anti-Semitic tropes, like the belief that the cabal is harvesting blood from abused children. QAnon's followers, who also believe there is a "deep state" effort to annihilate Trump, have peddled baseless theories surrounding mass shootings and elections and have falsely claimed that $5 \mathrm{C}$ cellular networks are spreading the coronavirus. Experts call these extreme, baseless claims "an incitement to violence" (Beckett, 2020; Vazquez, 2020; Liptak, 2020), since QAnon believers-who have not 
brought a single child abuser closer to justice-have radicalized people into committing crimes and taking dangerous or violent actions (Beckett, 2020) (Lawrence \& Davis, 2020).

The movement has been linked to several violent acts since 2018, with QAnon supporters arrested for threatening politicians, breaking into the residence of the Canadian prime minister, an armed standoff near the Hoover dam, a kidnapping plot, two kidnappings, and at least one murder (Beckett, 2020). The FBI named QAnon a domestic terrorism threat in 2019 (Jankowicz, 2021) and the Combating Terrorism Centre at West Point described it as a "novel challenge to public security" (Beckett, 2020). That threat nevertheless continued to grow (Jankowicz, 2021).

Like many others, David Lawrence and Gregory Davis (2020) also argue that QAnon is no longer just a conspiracy theory. As it stands today, QAnon is a decentralised, grand, and multifaceted phenomenon-a political movement and a quasi-religion. Marc-André Argention (2021) agrees that over the past four years, QAnon has evolved into an extremist religio-political ideology and a "hyper-real religion" (Argentino, 2020a). This hyper-real religion is based on the premise that pop culture shapes and creates actual reality, with examples including, but not limited to Heaven's Gate (Hafford, 2017), Church of All Worlds (Caw.com, 2021), Jediism (Lavelle, 2020), etc. Adrienne LaFrance (2020) is also among those who argue that QAnon represents the birth of a new religion. LaFrance underscores this argument by highlighting the apocalyptic tendencies found in QAnon; its clear-cut dualism between the forces of good and evil; the study and analysis of Qdrops as sacred texts; and the divine mystery of $\mathrm{Q}$.

According to Argentino, QAnon, as a movement is in a constant state of mutation and clearly blurs the boundaries between popular culture and everyday life. What this means is that technology and the marketplace of ideas have inverted the traditional relationship between the purveyors of religion and the consumers of religion. Some might argue that a hyper-real religion isn't a "real" religion because it's invented. QAnon is blatantly invented: it openly uses works of popular culture, media, entertainment, American evangelicalism, and conspiracy theories at its basis. Belief in QAnon reflects a created hyper-real world based on such theories (Argentino, 2020a). This situation is defined by Jules Evans(2021) as "conspirituality," which refers to the overlap between New Age/wellness culture and far-right conspiracy culture like QAnon.

Joseph Uscinski argues that QAnon's ideation resembles a cult. What $Q$ has done is to galvanize people around a set of ideas and weaponize them in a way that observers haven't normally seen (Brooks et al., 2020, 25:4427:46): Q's followers act more like a virtual cult, largely adoring and believing whatever disinformation the conspiracy community spins up (Murphy, 2020). Conspiracies themselves may not be new, but the internet has enabled fringe thinkers to "find their people;" and "the power of the social web" 
allows groups to spread from "a niche or regionally-specific cult to a global movement" (Brooks et al., 2020, 31:30-31:51).

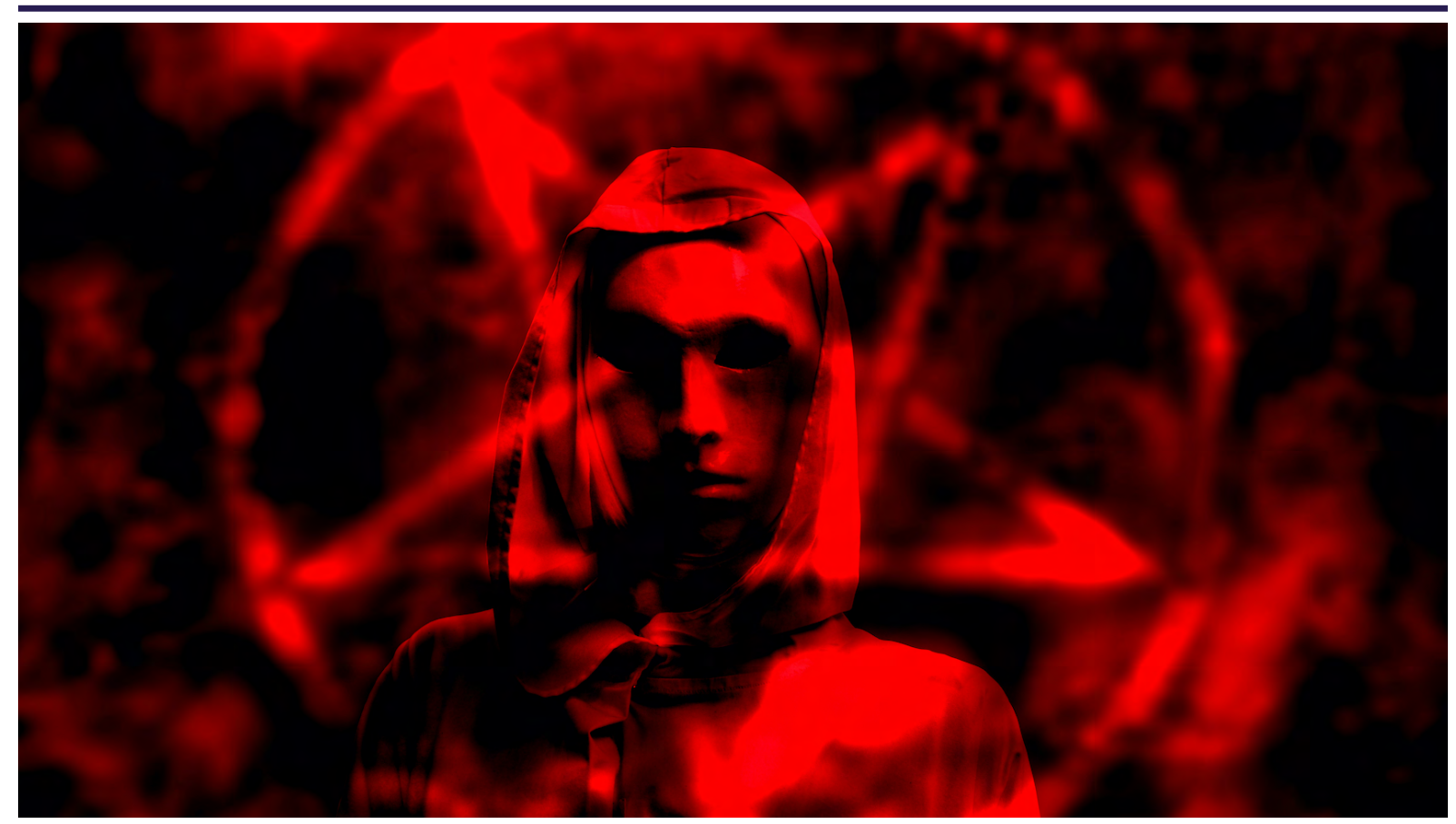

Paul Thomas (2020) sees many similarities between QAnon claims and prior rumour panics that employed satanic rhetoric. Thus, QAnon does not portray perceived political adversaries as merely having a difference of opinion, but as being downright evil. For example, in an Aug. 10, 2018 post, Q stated, "Many in Power Worship the Devil." On Aug. 26, 2020, Q posted an image suggesting that the 2020 Democratic National Convention logo resembled a Satanic Baphomet pentagram, which incorporates a goat's head and a five-pointed star. Accompanying text asserts that one party-the Republican party-discusses God while the other party—the Democratic party-discusses darkness. Such dialogue rises beyond the level of us versus them. Instead, QAnon elevates the conspiracy to a matter of cosmic good versus monstrous evil. Through that process, Qanon followers may see themselves as would-be monster-killers ready to use violence to remove evil (Thomas, 2020). While the religiously charged demonization of globalists dovetails with QAnon, religious maximalism has also gone mainstream. Under Trump, Republicans throughout the country have consistently situated American politics in the context of an eternal, cosmic struggle between good and evil. In doing so, they have rendered constitutional principles of representation, pluralism, and the separation of powers less inviolable (Mogelson, 2021).

Argentino writes in an article about the presence of a QAnon church operating out of the Omega Kingdom Ministry (OKM) - which is an existing model of neo-charismatic home churches as an offshoot of evangelical Protestant Christianity-and where QAnon conspiracy theories are reinterpreted through the Bible. In turn, QAnon conspiracy theories serve as a lens to 
interpret the Bible itself. The organization's spiritual adviser is Mark Taylor, a self-proclaimed "Trump Prophet" and QAnon influencer with a large social media following on Twitter and YouTube. OKM provides formalized religious indoctrination into QAnon (Argentino, 2020b).

Many of the people most prone to believing conspiracy theories see themselves as victim-warriors fighting against corrupt and powerful forces. They share a hatred of mainstream elites. That helps explain why cycles of populism and conspiracy thinking seem to rise and fall together. But QAnon is different. It may be propelled by paranoia and populism, but it is also propelled by religious faith. The language of evangelical Christianity has come to define the Q movement (LaFrance, 2020). The QAnon narrative is also inflected with shades of millenarianism: the battle between Good and Evil will end when the messianic President overthrows the Satanists, ushering in a new period of global prosperity. The role of orthodox QAnon influencers is to guide less well-informed adherents in much the same way as scholars interpret sacred texts for religious movements (Lawrence \& Davis, 2020).

Of course, QAnon also deserves to be studied for its various populists aspects. First of all, QAnon offers comfort in an uncertain and unprecedented age as the movement crowdsources answers to the inexplicable. It becomes the master narrative capable of simply explaining various complex events and providing solace for modern problems: a pandemic, economic uncertainty, political polarization, war, child abuse, etc. (Argentino, 2020a). Secondly, QAnon has an anti-establishment ideology rooted in a quasi-apocalyptic desire to destroy the existing, corrupt world and usher in a promised golden age (Argentino, 2021). Thirdly, it has a worldview characterized by a binary approach through a sharp distinction between the realms of "good" and "evil". Fourth, QAnon has an anti-science stance and unreasonable character. At its heart, QAnon is non-falsifiable. Belief in QAnon as the source of truth is a matter of faith rather than proof. Furthermore, by considering QAnon as a hyper-real religion, it becomes possible to frame how QAnon has found resonance not only within the American electoral system, but with populists around the globe. This is especially important in the context of framing the global response to the pandemic and public health. Last but not least, there's an increasing overlap between QAnon and the far-right/ patriot movements (Argentino, 2020a).

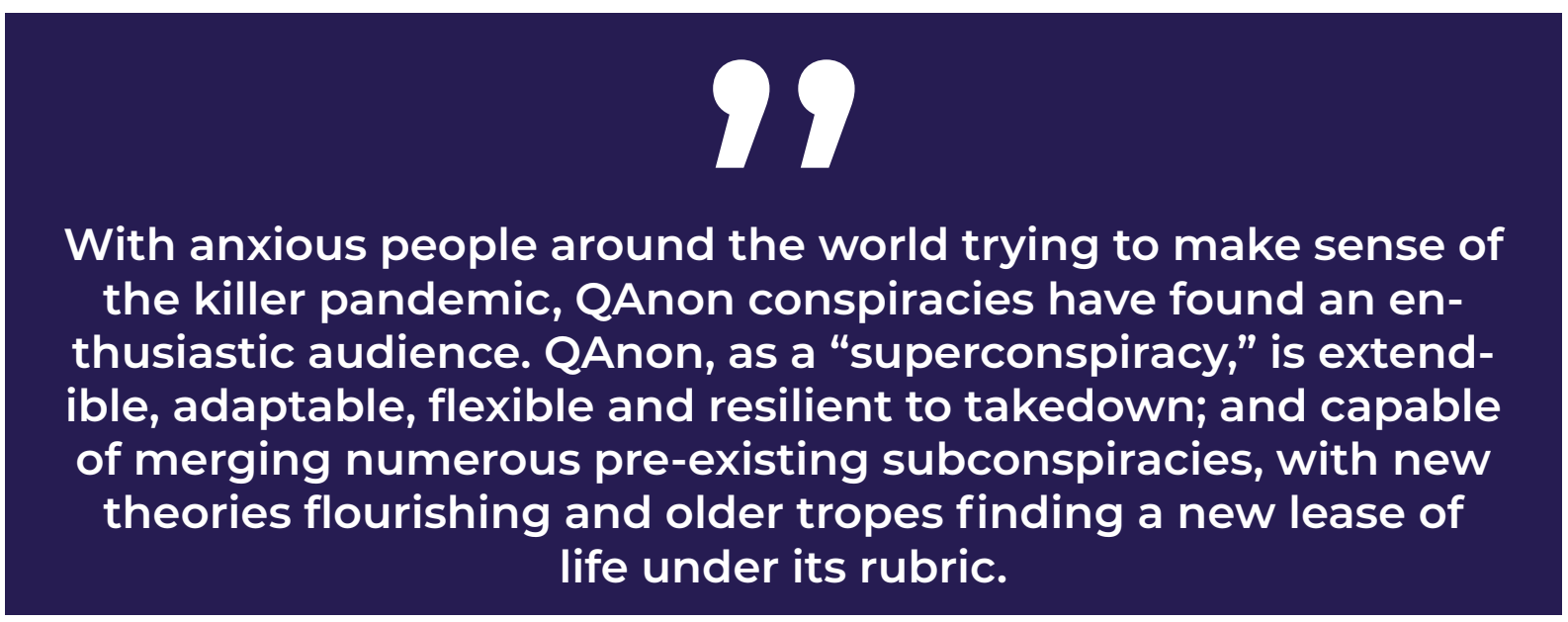




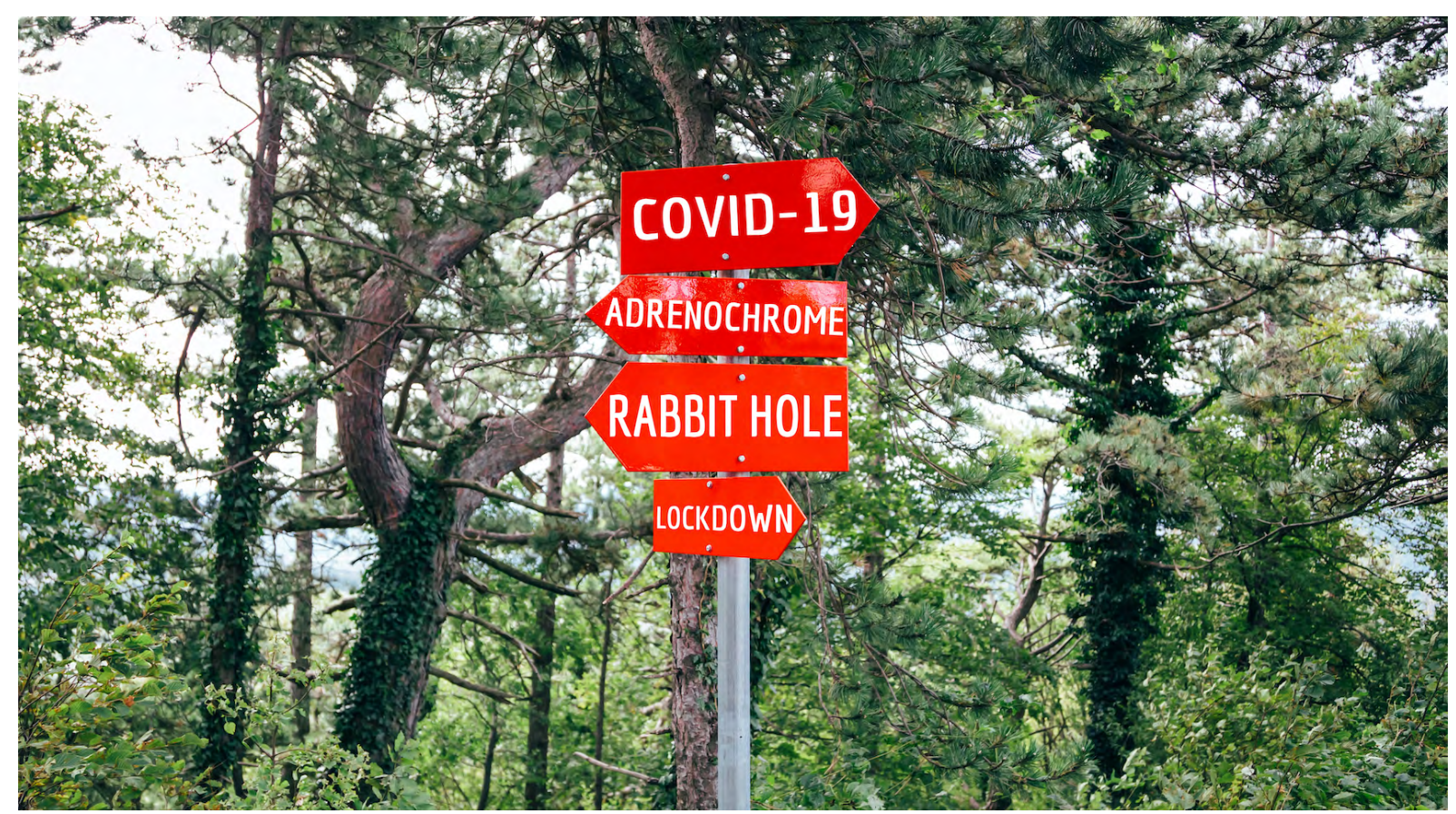

Social media campaign for coronavirus plus fake news and total disorientation in society. Photo: Iryna Budanova

\section{QAnon As Both Fertile Mother and Brainchild of Conspiracy Theories}

It is a widely accepted idea that conspiracy theories are born during times of turmoil and uncertainty. Fuelled by hysteria and unfounded claims of nefarious plots involving corruption and immorality practiced by unfeeling, immoral libertines, conspiracy theories emphasize the power that small cults of anti-human elites have upon the stability and established moral practices of a society (Kline, 2017). Conspiracy theories have been constant throughout history and existed since time immemorial, regardless of nationality, age, race, ethnicity, or any other marker of identity (Beene \& Greer, 2021), but 21st-century technological advancements have provided a powerful infrastructure for connecting conspiracy-minded individuals on a global scale (Smedt \& Rupar, 2020). Conspiracies tell a powerful story about the "zeitgeist" of a particular moment and of the deep uncertainties and anxieties of those who believe them, even if that story isn't true (Brotherton, 2016; Butter, 2020,
Uscinski, 2019).

Robert Brotherton (2013) defines conspiracy theories through several characteristics. First, conspiracy theories are unverified claims at odds with the mainstream consensus, and they grow and thrive because of their opposition to consensus (Brotherton, 2013: 10). Second, they are sensationalistic - of all the conspiracies throughout history, those that gain the most notoriety most often surround disasters, pandemics, terrorist attacks, celebrity deaths, political figures, plane crashes, and aliens (Brotherton, 2013: 10-11). Third, conspiracy theories assume everything is intentional, nothing is coincidental, and the world is divided into "good... struggling against evil" (Brotherton, 2013: 11). Fourth, those adhering to conspiracy theories have low standards of evidence. Lastly, conspiracy theories are epistemically self-insulating "against questioning or correction" (Brotherton, $2013,12)$. Therefore, the most successful conspiracy theories morph and evolve in order to stay relevant for followers (Beene \& Greer, 2021).

With anxious people around the world trying to make sense of the killer Covid-19 pandemic, QAnon conspiracies have found an enthusiastic audience hungry for the promise of salvation from tyran- 
ny at the end of a struggle dubbed "The Storm" (Farivar, 2020). While disinformation expert Joan Donovan describes QAnon as "a densely networked conspiracy theory that is extendible, adaptable, flexible and resilient to takedown" (Manjoo, 2020), several researchers argue that it is a "superconspiracy," capable of merging numerous pre-existing subconspiracies, with new theories flourishing and older tropes finding a new lease of life under its rubric (Lawrence \& Davis, 2020).

During the volatile 2016 US presidential campaign, a flurry of conspiracy theories erupted, aimed at demonizing the candidates. One of the most outrageous conspiracy theories-involving child sex trafficking, ritual murder, and cannibalism-is examined to reveal its archetypal elements and relevancy to hard-wired taboos shared by all of humanity(Kline, 2017; Farivar, 2020). The anarchical group's birth, and its continued seepage into mainstream American life, comes on the coattails of the Russian disinformation campaign that targeted US elections in 2016. While the Russian campaign had an apparent objective - to influence voters to elect Trump-QAnon is decentralized, having no clear objective aside from its popular slogan, "Question everything." However, there's no evidence that any of what QAnon claims is factual. Followers make unfounded claims and then amplify them with doctored or out-of-context evidence posted on social media to support the allegations. These theories have been further elevated through high-profile figures and organizations (Murphy, 2020).

QAnon has its roots in previously established conspiracy theories, some relatively new and some millennia old (Wong, 2020). The most recent precursor of QAnon is the "Pizzagate" theory that emerged ahead of the 2016 Presidential election, which alleged that Democratic politicians were trafficking children for use in paedophilic rituals (Lawrence \& Davis, 2020). Right-wing news outlets and influencers promoted the baseless idea of Pizzagate, which believes that references to a popular Washington DC pizza restaurant, Comet Ping Pong, in the stolen emails of Clinton campaign manager John Podesta were actually a secret code for a child trafficking ring (Wong, 2020).
The theory touched off serious harassment of the restaurant and its employees, culminating in December 2016, when a 28-year-old man named Edgar Maddison Welch, having driven from North Carolina to Washington, DC, fired an assault rifle inside Comet in a bid to rescue the children he thought were locked away there. No one was hurt. Welch was sentenced to four years in prison (Breland, 2019).

There are many threads of the QAnon narrative, all as far-fetched and evidence-free as the rest, including subplots that focus on John F Kennedy Jr. being alive (he isn't), the Rothschild family controlling all the banks (they don't), and children being sold through the website of the furniture retailer Wayfair (they aren't) (Wong, 2020). The frantic, independent theorising of QAnon followers has proved capable of rolling any event into its grand narrative, from the momentous-such as the JFK assassination or the sinking of the Titanic-to the seemingly insignificant, such as the mispricing of items on the retail site Wayfair or a "hidden symbol" in a frame of a Disney film. This gives QAnon a certain fluidity: in some cases, adherents of the broader ideology might choose to emphasise certain aspects and minimise others as part of a calculated effort to maximise its appeal (Lawrence \& Davis, 2020). Therefore, it is not illogical to say that QAnon, like other conspiracy theories, is fundamentally a form of political propaganda to mobilize people (Tollefson, 2021).

However, the most striking part of the QAnon conspiracy theory is, perhaps, the fact that its followers believe that Trump is waging a secret battle against the cabal of devil-worshipping cannibal paedophiles (O'Donnell, 2020) and its "deep state" collaborators to expose the malefactors and send them all to Guantánamo Bay (Wong, 2020). Media scholars Whitney Phillips and Ryan M. Milner (2020) argue that the claims about the existence of a "deep state" have a long history in America (Bodner, 2021: 144), as it has antecedents in influential 20th century political conspiracy thinking found in places like the John Birch Society, even if the term itself is not native to the US (Bodner, 2021: 145).

Ryan Gingeras (2019), who minutely details the term's history, finds it first 
emerging in Turkey to explain the disparity between the apparent government and the relationship and influence of organizations within the state, the armed forces, and organized crime, each of which act as forms of parallel government. Turkey's long history of coups, civil wars, and extrajudicial killings of political enemies makes the "deep state" a common way for Turks to understand their government and history. After 2000, the term is widely used in academic literature to discuss not only Turkey but other Middle Eastern countries (Bodner, 2021: 145).

In the eyes of QAnon followers, the "deep state" actors in the US context are Democrats, especially those left over from the Obama administration (Bodner, 2021: 144). The concept has also been partially shaped and nurtured into a more precise form of official political conspiracy theory by Steve Bannon, former chief strategist to former President Trump. Published under a pen name, the term was introduced on Bannon's website Breitbart News a month after Trump's election (Virgil, 2016) and heavily promoted ever since (Bodner, 2021: 145). A public poll in March 2018 showed that 37 percent of respondents had heard of the "deep state" (Bodner, 2021: 146).

The utility of the "deep state" hypothesis to Trump is clear, since it is an absent and voiceless enemy that excuses any and all of his failures. For the last 12 years, Alex Jones-and since 2017, QAnon-have spent their time recycling and recontextualizing several traditional right-wing conspiracy traditions to repopulate the "deep state" with the correct kind of enemies. Democrats are an obvious choice. For wealthy businesspeople, they have substituted George Soros, amorphous "elites," and Hollywood celebrities (Bodner, 2021:

146) QAnon has also amplified the rare appearance of a conspiracy category called "the benevolent conspiracy," arguing that Trump and a surprising gang of allies are conspiring from within the government to bring down the "deep state" (Bergmann 2018: 52). If Trump won in November 2020, QAnon would be vindicated in their beliefs and said this is what God had mandated, reinforcing the belief that they were right. Since Trump lost, it was attributed to the "deep state" Luciferian cabal (Argentino, 2020a).

For many QAnon believers, the naturally-occurring chemical compound adrenochrome, produced by the oxidisation of adrenaline, is at the heart of the conspiracy. It is a potent drug/elixir of youth harvested by the cabal from the adrenal glands of children, who are tortured to intensify the drug's effects (Lawrence \& Davis, 2020). A cabal of elites didn't just harvest children's blood: they consumed the flesh itself. As proof, conspiracy theorists pointed to a website that falsely claimed that Raven Chan-Mark Zuckerberg's sister-in-law-was involved with a fake restaurant called the Cannibal Club. Although the story has since been debunked, it's alive and well on social media (Evans, 2020). Adrenochrome is real-it has hallucinogenic compounds-but everything else about this narrative is fiction. The origin of this concept is easily linked to Hunter S. Thompson's novels Fear and Loathing in Las Vegas (1972) and Fear and Loathing on the Campaign Trail '72 (1973). Thompson's character "Dr. Gonzo" says adrenochrome has to come from "the adrenaline glands from a living human body." That the bodies are children is a QAnon addition (Bodner, 2021: 158)

The use of exotic drugs by dangerous deviants is a traditional element in several previous legends and conspiracy theories about endangered children (Brunvand, 2001). However, QAnon shifted the focus from enemies within to enemies abovenamely, members of the "deep state." Thus, QAnon has weaponized fears over Satanism and child harm and shoehorned them into conspiracy thinking associated with the "deep state" (Bodner, 2021: 163). The essential problem is that this conspiracy theory's central narrative subverts legitimate concerns about child trafficking and child abuse with fantastical misinformation and anti-Semitic tropes, fostering dangerous anger in the process. It also risks obscuring genuine child abuse and hampering legitimate efforts to better child welfare (Lawrence \& Davis, 2020).

Conspiracy theories and populism both employ a binary worldview that divides societies between corrupt or evil elites and the pure or unknowing people, a framework that contextualises fears and 
hardships by personifying them into an identifiable enemy (Lawrence \& Davis, 2020). Gregory Stanton (2020), the founder of the Genocide Watch, says many people are perplexed at how any rational person could fall for such an irrational conspiracy theory. But modern social science shows that people in groups don't always think rationally. They respond to fear and terror. They blame their misfortunes on scapegoats. They support narcissistic demagogues they hope will rescue them (Stanton, 2020).

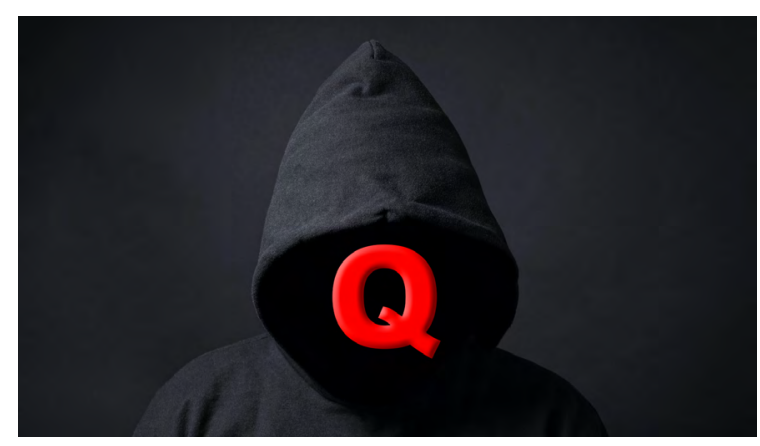

Photo: Axel Bueckert

\section{What Does "Q" Stand For, or, Who Is "Q"?}

On October 28, 2017, the anonymous user now widely referred to as "Q" appeared for the first time (LaFrance, 2020; Lawrence \& Davis, 2020) on the message board 4chan. In a thread called "Calm Before the Storm" and in subsequent posts, Q established his legend as a government insider with top (Q-level) security clearance (Martineau, 2017; Bodner, 2021: 147) who knew the truth about a secret struggle for power involving Trump, the "deep state" (Winter, 2019), Robert Mueller, the Clintons, paedophile rings, and other elements. Since then, $\mathrm{Q}$ has continued to drop "breadcrumbs" on 4chan and 8chan, fostering a "QAnon" community devoted to decoding "Q"s messages and understanding the real truth about everything (Wong, 2018).

Anonymous internet posters claiming to be high-level government officials are not entirely uncommon: in recent years, other so-called "anons" have emerged with claims that they were revealing secrets from inside the FBI or CIA. But "Q" is the first such figure to have achieved such a broad audience and real-world political influence. This is largely due to the activism of three dedicated conspiracy theorists-Pamphlet Anon or Coleman Rogers, BaruchtheScribe or Paul Furber, and YouTuber Tracy Diaz-who latched onto Q's posts in the early days and translated them into a digestible narrative for mainstream social media networks. The three built and shepherded the Q-community by expanding it to more accessible platforms like YouTube and Reddit and finding homes for the community when various sites shut them down, like Reddit and 8chan eventually did (Zadrozny \& Collins, 2018; Bodner, 2021: 149).

These activists worked to develop a mythology and culture around QAnon and cultivated an audience for it on mainstream social media platforms. (Zadrozny \& Collins, 2018). According to Julia Carrie Wong (2020), QAnon might have faded away as well, were it not for the dedicated work of these three conspiracy theorists. Despite being de-platformed from numerous social media venues, there exists an entire QAnon media ecosystem, with enormous amounts of video content, memes, e-books, chatrooms, and more, all designed to snare the interest of potential recruits, then draw them "down the rabbit hole" and into QAnon's alternate reality (Wong, 2020) -all allegedly leading to a "Great Awakening" (Wong, 2020a).

"Q" has been communicating Trump's plans to all brave patriots with ears via encoded online messages known as "Qdrops." When the time is right, Q will give the signal and the people will rise up and join Trump in one final Armageddon-like showdown against the forces of darkness-an event that QAnon adherents call "the Storm" (Bracewell, 2021).

"Q" first attracted attention with a wild premonition: Former Secretary of State and Trump's Democratic rival Hillary Clinton would soon be arrested, and riots would ensue. The prediction, needless to say, proved false, as did many others that followed, including the forecast of mass indictments of other Democrats. But that did not stop $Q$ from continuing to 
post about Trump's "secret war" against a deep state cabal of paedophiles, with his "Qdrops" parsed and amplified by a growing ecosystem of believers (Farivar, 2020).

Despite rampant speculation, no one has unravelled the mystery person behind Q. Outside QAnon circles, few take him as a real insider. Many experts believe more than one person may have been behind the $Q$ account over the years (Farivar, 2020). Until July 2020, QAnon supporters believed that "Q" was a high-ranking Trump administration official, or maybe even Trump himself. But now, a good portion of QAnon believers have become convinced that $\mathrm{Q}$ is none other than JFK $\mathrm{Jr}$, even though he died in a plane crash more than 20 years ago. (Sommer, 2018).

July 2018 was a rough month for QAnon followers. After making a post on July 4th, $\mathrm{Q}$ didn't leave any clues for 20 days, marking the longest gap between $Q$ hints since the scheme began. Around the middle of July, the anonymous poster, who was soon dubbed "Ranon," posited that Kennedy hadn't actually died in a plane crash. Instead, he'd faked his death to avoid the supposed deep-state cabal and teamed up with Trump to kick off a decades-long strategy. While Trump laid the groundwork for his presidential bid, Kennedy had become Q. In late July 2018, "Q" returned to posting and denounced " $R$," its newfound rival for impressionable Trump supporters. Still, the Kennedy theory persists among a segment of QAnon believers (Sommer, 2018).

"Q"s posts are cryptic and elliptical. They often consist of a long string of leading questions designed to guide readers toward discovering the "truth" for themselves through "research". Despite "Q" having consistently made predictions that have failed to come to pass, true believers tend to simply adapt their narratives to account for inconsistencies. For close followers of QAnon, the posts (or "drops") contain "crumbs" of intelligence that they "bake" into "proofs." For "bakers," QAnon is both a fun hobby and a deadly serious calling. There are subcultures within QAnon for people who approach studying Qdrops in a manner similar to Bible study (Wong, 2020). Like medieval scholars engaged in interpretation of metaphysical texts, readers have constructed elaborate illuminated manuscripts and narrative compilations (Tuters, 2020).Moreover, those who subscribe to Qdrops are presented with elaborate productions of evidence in order to substantiate QAnon's claims, including source citation and other academic techniques (Argentino, 2020a).

\section{Commenting that the Seventh-day} Adventists and the Church of Jesus Christ of Latter-day Saints are thriving religious movements indigenous to America, Adrienne LaFrance talks about the possibility of QAnon becoming another. "It already has more adherents by far than either of those two denominations had in the first decades of their existence. People are expressing their faith through devoted study of Qdrops as instalments of a foundational text, through the development of Q-worshipping groups, and through sweeping expressions of gratitude for what $Q$ has brought to their lives. Does it matter that we do not know who $Q$ is? The divine is always a mystery. Among the people of QAnon, faith remains absolute. True believers describe a feeling of rebirth, an irreversible arousal to existential knowledge. They are certain that a Great Awakening is coming," (LaFrance, 2020).

There are around 5,000 posts attributed to $Q$ in an online archive. Q's posts are purposefully cryptic in order to protect his cover-or, alternatively, to employ the common stereotype of the commercial fortune teller's trick: to make a statement as broadly applicable across any number of possibilities. Q's posts cryptically refer to a dizzying array of current events and various conspiracy theories (Bodner, 2021: 147). In analysing the Qdrops, Paul Thomas (2020) has noted a discourse of evil woven throughout Q's messages. Peppering the Qdrops are claims like "many in our government worship Satan." According to Anons, Trump is engaged in a battle of cosmic significance between the "children of light" and the "children of darkness" (Thomas, 2020).

The QAnon universe is sprawling and deep, with layer upon layer of context, acronyms, characters, and shorthand to learn. The "castle" is the White House. "Crumbs" are clues. CBTS stands for 
"calm before the storm," and WWGTWGA stands for "Where we go one, we go all," which has become an expression of solidarity among $\mathrm{Q}$ followers. There is also a "Q clock," which refers to a calendar some factions of $Q$ supporters use to try to decode supposed clues based on time stamps of Qdrops and Trump tweets (LaFrance, 2020). QAnon supporters have likened Qdrops to Hansel and Gretel-like breadcrumbs (Murphy, 2020).

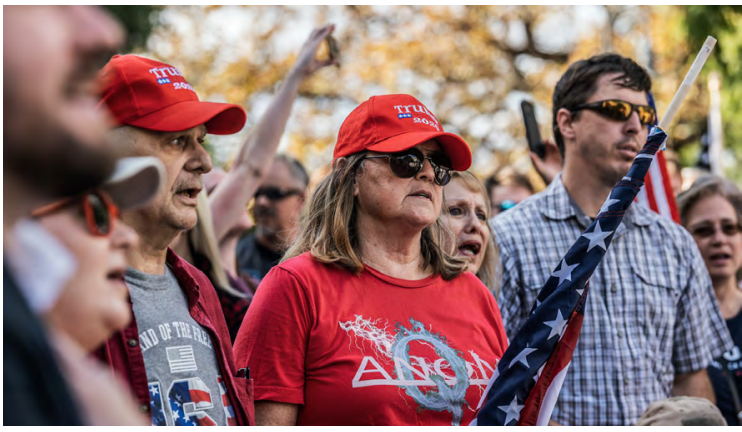

Trump supporters and some QAnon followers march around the SC State House in protest of Joe Biden (D) wining the 2020 presidential election in Columbia, South Carolina, November 7, 2020. Photo: Crush Rush

\section{Who Are QAnon Adherents?}

For the first two and a half years of its existence, QAnon attracted a devoted but relatively small coterie of followers. However, in the spring of 2020, as the Covid-19 pandemic forced millions of people to hunker down at home and made the internet their almost exclusive connection to the outside world, QAnon's popularity exploded (Bracewell, 2021).QAnon does not possess a physical location, but with its infrastructure, literature, growing body of adherents, and great deal of merchandising QAnon is now much more than a loose collection of conspiracy-minded chat-room inhabitants. As Adrienne LaFrance (2020) underlined, it is a movement united in mass rejection of reason, objectivity, and other Enlightenment values. The group harnesses paranoia to create fervent hope and a deep sense of belonging, and they are demonstrating the ability to produce, share, and tie together worldviews that distort and shatter reality, creating an environment that resembles the birth of new religion (Smedt \& Rupar, 2020) and political ideology (Argentino, 2020c).

It's impossible to know the number of QAnon adherents with any precision, but the ranks are growing. While $Q$ has hopped from one fringe imageboard to another, his followers have thrived on mainstream platforms: Facebook, Twitter, YouTube, and Telegram. On any given day, even in the first half of 2020, an estimated 300,000 to 400,000 people posted about QAnon on Facebook, Twitter, and Telegram, according to Argentino, who says that it would be a mistake to dismiss them as "Iunatics with tin foil hats living in their parents' basement" (Farivar, 2020).

QAnon has gained traction as a political force, especially in the Republican party. 97 congressional candidates embraced QAnon during the 2020 election cycleincluding two who won. In total, 89 of the candidates were Republicans, two were Democrats, one was a Libertarian, one was a member of the Independent Party of Delaware, and four were independents (Kaplan, 2020). It is not a secret that QAnon is most popular among older Republicans and evangelical Christians. Other followers appear to have come to QAnon from New Age spiritual movements, from more traditional conspiracy theory communities, or from the far right. Since adulation for Trump is a prerequisite, it is almost exclusively a conservative movement, though the \#SaveTheChildren campaign is helping it make inroads among non-Trump supporters (Wong, 2020).

However, QAnon has developed beyond its roots in the intensely hyper-partisan and US-centric right, moving from a niche far-right interest that Lawrence and Davis (2020) have termed "orthodox QAnon" into a broader, less uniform type they call "eclectic QAnon." This development has enabled the theory to gain supporters from across the political spectrum and of diverse backgrounds.

QAnon nearly reached the main stage of the Republican Party at Trump's July 31, 2018 rally in Tampa, Florida, where signs reading "We are Q" and "Q" appeared near the front of the crowd during his speech. Four months later, Vice President Pence 
posted-and then deleted-a photo on Twitter with a law enforcement officer wearing a QAnon patch on his uniform. And in July 2019, the White House invited a QAnon supporter to a "social media summit" (Murphy, 2020).An NPR/Ipsos poll conducted in fall 2020 found that nearly a quarter of Republicans believed the outlandish core claim of the QAnon conspiracy theory. Therefore, Francis Fukuyama (2021) argued that the Republican Party is no longer a party based on ideas or policies but something more akin to a cult. Uscinski also said most QAnon followers are Trump supporting evangelicals who are predisposed to believe a pro-Trump, anti-liberal narrative (Wong, 2018).

With a brand ambassador like the "QAnon shaman," it's easy to dismiss QAnon followers as deranged, troubled, and isolated. But that is not the case, according to Brent Giannotta (2021). Most QAnon followers lead largely mainstream lives. A survey by the American Enterprise Institute found that 27 percent of white evangelicals nationwide believe in QAnon. That percentage is higher than any other faith group surveyed, and more than double the support for QAnon beliefs among Black Protestants, Hispanic Catholics and non-Christians (Colarossi, 2021). Flags seen at the Jan. 6 insurrection read, "Jesus is my saviour, Trump is my president." Making the jump from religious devotion to conspiracy theories requires an animating emotion-namely, anger (Giannotta, 2021).

For all the focus on QAnon on the "supply side," the "demand side" is an even greater concern. As the journalist Charlie Warzel stresses, "Millions of Americans are actively courting conspiracies and violent, radical ideologies in order to make sense of a world they don't trust" (Goldgeier \& Jentleson, 2021). More than one in three (39\%) Americans believe in the existence of a so-called "deep state" which was working to undermine President Trump - another tenet of QAnon (Ipsos, 2020). Also, as many as one-third of Republicans believe QAnon to be "mostly true" (Rothschild, 2020), and almost half (47\%) of Americans say they have heard of QAnon, as of September 2020 (Mitchell et al., 2020).

Since QAnon expanded onto YouTube and Facebook, the movement has seen its ranks swollen by Baby Boomers (those born between 1946 and 1964). White Boomers overwhelmingly supported Trump in 2016, and they have also become enthusiastic transmitters of conspiracy theories via social media (Binder 2018; Bodner, 2021: 150). Many of QAnon's supporters are middle-aged whites, many with stable jobs and businesses (Giannotta, 2021). Though academic research would suggest that conspiracy theories are for "losers," QAnon has thrived. After all, the community propagating the QAnon conspiracies was on the winning side of the 2016 US presidential election (Argentino, 2020c).

According to QAnon adherents, the eventual destruction of the global cabal can be accomplished only with the support of patriots who search for meaning in clues posted by $\mathrm{Q}$, who requires followers to reject mainstream institutions, ignore government officials, battle apostates, and despise the press (LaFrance, 2020). A large number of $Q$ supporters believe in-and are increasingly vocal about-demons as active forces in American life and politics. Trump's alleged battle against the "deep state" here adopts cosmic meaning, as not only the US government but undocumented immigrants and Black and LGBTQ people are cast as agents of demonic forces (Greenwood, 2020). In this regard, QAnon has many overlaps with spiritual warfare and its practitioners. It uses similar ideas of religious revival and donning the "armour of God" against unseen foes (O'Donnell, 2020). 


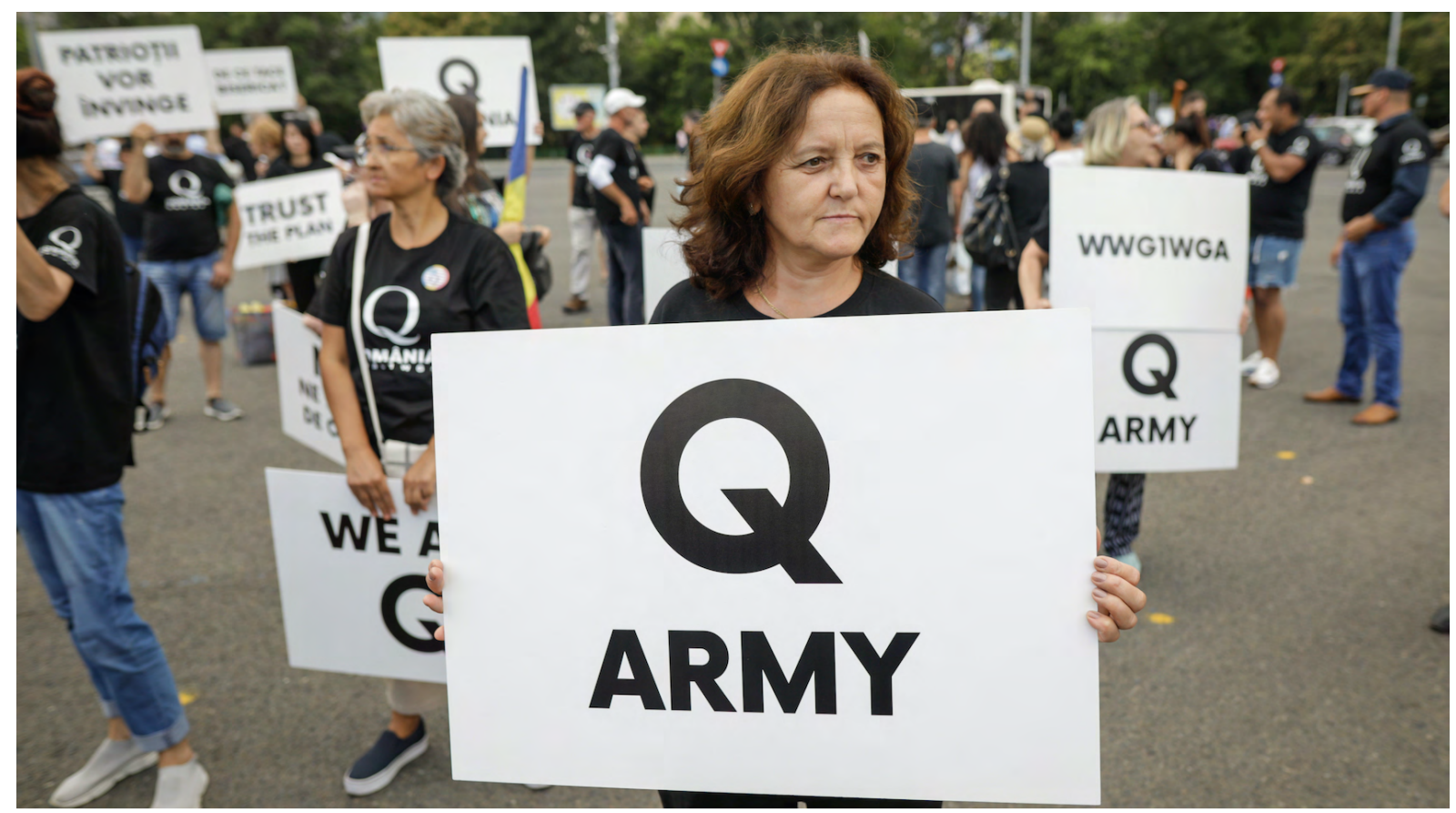

People display Qanon messages on cardboards during a rally in Bucharest, Romania on Aug. 10, 2020. Photo: M. Moira

\section{Women of the Move- ment: Pastel QAnon}

In parallel to the findings of Daniel Halpern and his colleagues, who argue women and people with politically right-leaning views are more likely to share conspiracy theories (Halpern et al., 2019), QAnon has gained popularity among women (Butler, 2020). According to numerous reports, a significant number of QAnon followers are women introduced to QAnon ideology through images, videos, and stories shared by some of the most popular beauty, lifestyle, and parenting influencers on social media (Breland, 2020; Butler, 2020; Flora, 2020; Kelly, 2020; Tiffany, 2020). These women are using warm and colourful images to spread QAnon theories through health and wellness communities and by infiltrating legitimate charitable campaigns against child trafficking. Argentino names this as "Pastel QAnon," which exists in adjacent lifestyle, health, and fitness communities and softens the traditionally raw QAnon narratives to spread the conspiracies to new audiences (Argentino, 2020).

It is not surprising that QAnon's message would resonate in virtual spaces to which millions of women turn every day for advice on how to optimize the health and wellbeing of themselves and their families. Mothers, upon whom a disproportionate share of the burdens of pandemic-era child-rearing have fallen, are trying to keep their children safe and healthy. The QAnon movement ministers to their anxiety by providing them a window into an alternative reality in which the Coronavirus is a hoax and the "real" threat to their children is the deep-state cabal (Seitz and Swenson, 2020). As one QAnon adherent at a "Freedom for the Children" rally in London put it, "Saving our children is far more important than a fake pandemic" (Kelly, 2020; Bracewell, 2021). So sprawling is the QAnon universe that it seems to be able to adapt to prey on the specific fears of subgroups. In the case of mothers, of course, that's kids. So, some members used moms' groups to organize in-person rallies against child trafficking and what they believed was rampant paedophilia under the \#saveourchildren QAnon hashtag. Many moms who shared these ideas didn't know that they were part of a broader conspiracy theory (Butler, 2020).

Many female QAnon believers are "lifestyle influencers, including mommy pages, fitness pages, diet pages, and "alterna- 
tive healing" accounts. "These influencers provide an aesthetic and branding to their entire pages, and they, in turn, apply this to QAnon content, softening the messages, videos and traditional imagery that would be associated with QAnon narratives," Argentino wrote. QAnon influencers-some with substantial followingspost images of quotes with baby-pink and sky-blue palettes that read:"\#whereareallthechildren," "COVID is over," and "child sex trafficking is not a conspiracy theory." Several posts from users speak of the journey down the "rabbit hole," the so-called "great awakening," and being "red-pilled," a reference from The Matrix which conspiracy theorists use to describe "sudden enlightenment" (Gillespie, 2020). The enormously affecting idea that thousands of children are being kept captive in dungeons and tunnel networks across the world has drawn in many who might otherwise have rejected the heavily proTrump and narrow political narratives of QAnon (Lawrence \& Davis, 2020).

According to Lydia Khalil, research fellow at Deakin University, there is a history within the wellness community which has been anti-establishment and very sceptical of big pharma; the QAnon conspiracies tend to feed into this. Adding to this, QAnon has also co-opted certain sayings or hashtags that will resonate with the community. \#TheGreatAwakening is one of the group's main hashtags and followers often talk about "waking up to the truth," which are common phrases in new age spirituality practices such as yoga and meditation (Aubrey, 2020). Therefore, some influencers have even felt compelled to speak out against the QAnon movement. Seane Corn, a yoga teacher with 108,000 followers, wrote on Instagram that "QAnon's agenda is to use manipulative means to recruit folks who are rightfully scared, angry and disillusioned with the state of our nation" (Gillespie, 2020).

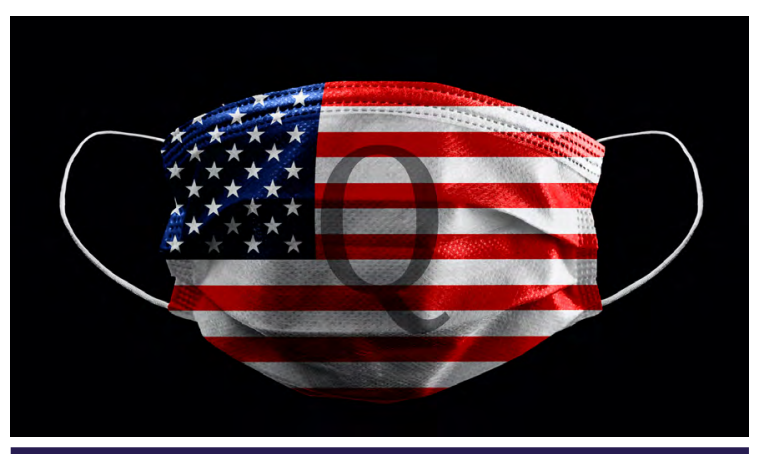

\section{Pandemic Accelerates and Widens QAnon's Reach}

The COVID-19 pandemic gave rise to many conspiracy theories, including the idea that the pandemic is part of a plan imposed by world elites to vaccinate most of the world's population (Labbe et al., 2020). The pandemic has created an environment of uncertainty, distrust, fear, and powerlessness, and QAnon has successfully taken advantage of this atmosphere by expanding the scope of the conspiracy theory and using it to spread misinformation and fake news about an already complex and unsolved public health crisis. QAnon supporters have also managed to garner support for the antivaccine movement and anti-lockdown protests. In this regard, COVID-19 has become a vital part of the QAnon movement itself (MDI, 2020; Wong, 2020) and a boon for the movement in terms of new members (Argentino, 2020c). QAnon has grown louder by attaching itself to scepticism about the pandemic and fears over $5 \mathrm{C}$ and vaccination (Aubrey, 2020), as well as to theories that the coronavirus was engineered to earn money for vaccine makers (Tollefson, 2021).

In his long-winded "drop" on July 31, 2020 , Q ranted that the coronavirus pandemic was partly designed to help "shelter" presumptive Democratic presidential nominee Joe Biden from appearing in public and participating in debates and to "eliminate" or delay Trump rallies (Farivar, 2020). A simple narrative explained that Trump was using the lockdown, especially travel restrictions, to prevent Satanic elites from escaping overseas before he could arrest them; and the stay-at-home orders 
would protect citizens during mass military actions (Mantyla, 2020). In other variations, the lockdowns provided cover for more complex military operations against the child traffickers (Bodner, 2021: 156).

The number of QAnon Facebook group members has jumped 800 percent to 1.7 million while Twitter accounts that post on QAnon related hashtags have increased 85 percent to 400,000 during the pandemic (Farivar, 2020). As the pandemic took hold, QAnon became a hotbed for medical misinformation. Analyses by Gallagher, the social media researcher, and the New York Times demonstrated how QAnon groups fuelled the viral spread of "Plandemic," a 26-minute video chock full of dangerously false information about Covid-19 and vaccines. Facebook's algorithms appear to have detected this synergy between the QAnon and anti-vaccine communities (Wong, 2020a).

According to Kiera Butler (2020), it all started with a trickle of odd posts when lockdowns began in March 2020. First, came the questions about social distancing measures; then there were posts with pseudoscientific "research" about how masks make coronavirus worse and social distancing can weaken the immune system. In May, Plandemic appeared and after that, the trickle of memes became a torrent (Butler, 2020). The exponential growth of QAnon has dovetailed with a boom of COVID-19 conspiracy theories, which include claims that 50 radiation is the cause of the health crisis and/or that a potential vaccine will contain a microchip to track populations. This is at least in part due to the efforts of $Q$, who has repeatedly suggested that measures to control the pandemic were part of a plot to subvert the US election. QAnon followers have variously speculated that the virus is either entirely fabricated or a deep state bioweapon to allow for election rigging, scuppering Trump's "Plan" and allowing the cabal to tighten their totalitarian grip; prominent figures in the fight against COVID-19, such as Bill Gates and Anthony Fauci, have been widely condemned as members of the cabal (Lawrence \& Davis, 2020).

In fact, during the pandemic, most of Q's posts proved derivative, reinforcing stan- dard conspiracy thinking about the virus. Unlike the supposed insider information that early $Q$ drops pretended to offer, pandemic-era $Q$ presents no secret or privileged information (Bodner, 2021: 151152). Seema Yasmin, a Stanford physician and expert on health misinformation, says conspiracies thrive in the absence of clear and consistent guidance from leaders. As the pandemic wore on, the Trump administration continued to contradict itself, sending mixed messaging on testing, schools, masks, and social distancing - not to mention the possible vaccine. Parents were left to their own devices, relying on incomplete information to keep their families safe. She said, "Charlatans are plugging those knowledge gaps. They're saying completely false things with a sense of authority," (Butler, 2020). QAnon is a significant force during the pandemic because of its reach into the very heart of the Trump Administration and the GOP (Bodner, 2021: 144). 


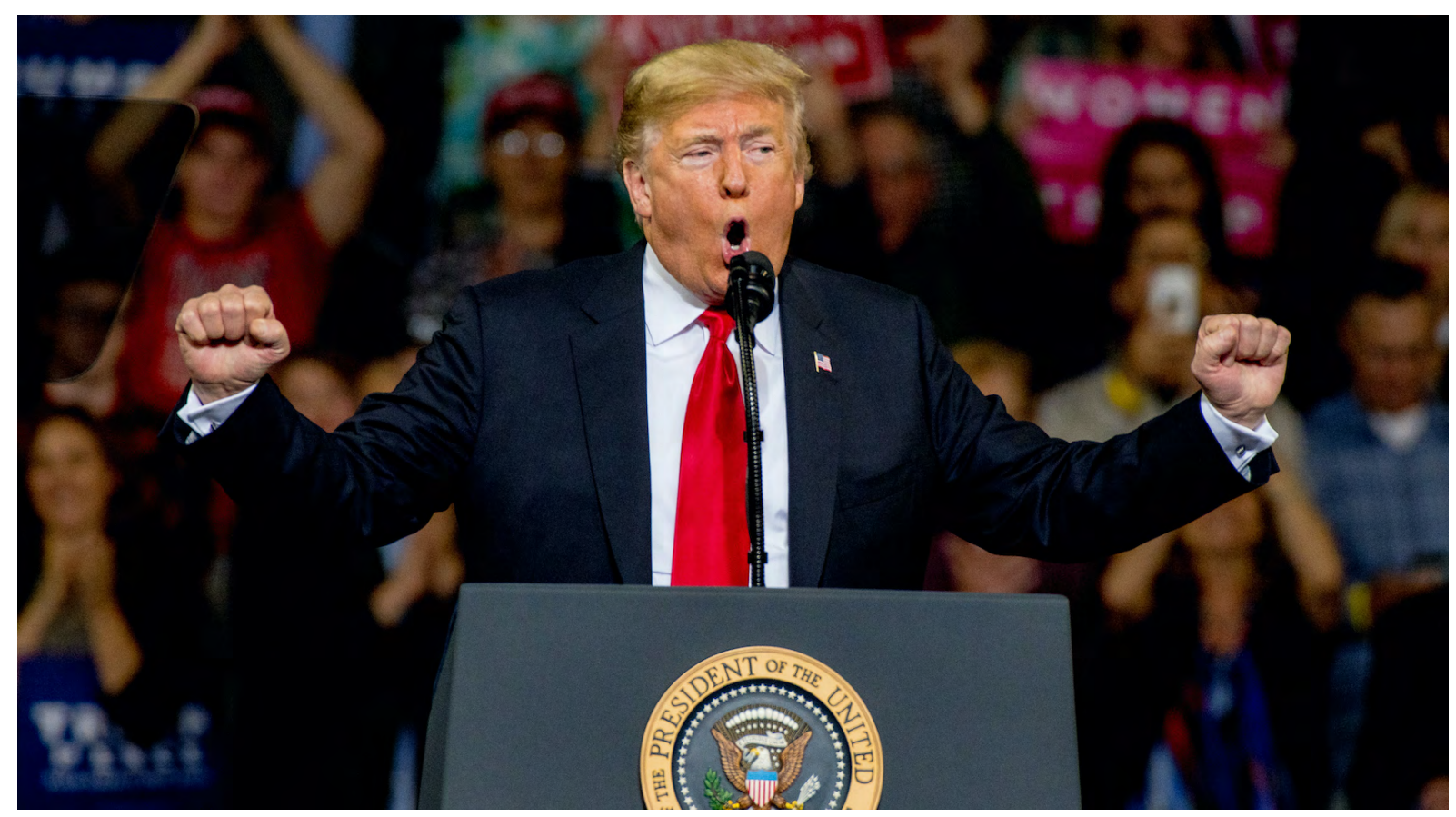

Former US President Donald Trump at rally in support of Kansas Secretary of State Kris Kobach who is the Republican candidate for governor in Topeka Kansas, USA on October 6, 2018. Photo: Mark Reinstein

\section{QAnon's Ties With Trump As \\ Conspiraist-in-Chief}

The QAnon conspiracy gained adherents throughout the US as the 2020 presidential and congressional campaigns heated up. Trump-who proved himself to be conspiracist-in-chief (Evans, 2020)-is revered among the conspiracy's followers, who believe he was recruited to help eliminate the criminal conspiracy they allege is gripping the world's power structures. Trump has repeatedly retweeted messages from accounts that promote QAnon while more than a dozen Republican candidates running for Congress have embraced some of its tenets (Farivar, 2020). Before he was banned, he amplified tweets from supporters of QAnon at least 185 times (Kaplan, 2021), including more than 90 times following the start of the pandemic (Argentino, 2020c).

Trump associates-such as his personal lawyer Rudy Giuliani, campaign manager Brad Pascale, former national security adviser Michael Flynn, and son Donald Trump Jr.--have all amplified QAnon content as well. Trump's son Eric Trump promoted QAnon on Instagram when plugging the president's controversial rally that was held in Tulsa, Oklahoma (Argentino, 2020c) on June 20, 2020. He deleted the image relatively quickly, but not before screenshots spread across the Facebook Q-sphere. "So Eric Trump posted a pic with a 'Q' in the imagery," an administrator of one of the larger QAnon groups wrote. "The pic has been taken down but the message was received!" (Wong, 2020a).

Although he never endorsed QAnon, Donald Trump repeatedly refused to condemn the conspiracy theory and once praised its followers for their support (Tollefson, 2021). He claimed that all he knows about the movement is that "they are very much against paedophilia" and that he agrees with that sentiment (Vazquez, 2020). Trump's refusal to denounce QAnon throughout his term further strengthened the movement, whose members, unsurprisingly, helped push the president's false allegations of a "rigged election." Activists from across Trump's base-who all bought into that disinformation narrative-arrived en masse at the US Capitol on January 6 with the express goal of overturning the democratic process, causing mayhem, and shaking the 
country to its core (Jankowicz, 2021).

During a town hall meeting, Trump also tried to separate himself from his retweet of a conspiracy theory from an account linked to QAnon, which baselessly claimed that former Vice President Joe Biden orchestrated the killings of Seal Team Six to cover up the fake death of al Qaeda founder Osama bin Laden. "I know nothing about it," Trump claimed. "That was a retweet - that was an opinion of somebody. And that was a retweet. I'll put it out there. People can decide for themselves" (Vazquez, 2020).

He also refused to condemn the group in August 2020 and went so far as to embrace their support. "I don't know much about the movement other than I understand they like me very much, which I appreciate," Trump said (Liptak, 2020). "I have heard that it's gaining in popularity," Trump added, suggesting QAnon followers approved of how he'd handled social unrest in places such as Portland, Oregon. "I've heard these are people that love our country and they just don't like seeing it." Trump has also defended his decision to endorse Republican congressional candidate Marjorie Taylor Greene in Georgia, despite her history of promoting QAnon theories and making racist and anti-Semitic remarks (Vazquez, 2020).

On August 19, 2020, at a White House press briefing, asked if he believed the crux of the theory, described by a reporter as the belief that he "is secretly saving the world from this satanic cult of paedophiles and cannibals," Trump said: "Well, I haven't heard that, but is that supposed to be a bad thing or a good thing?" He went on, "If I can help save the world from problems, I'm willing to do it. I'm willing to put myself out there. And we are, actually, we're saving the world from a radical left philosophy that will destroy this country and, when this country is gone, the rest of the world will follow" (Liptak, 2020; Wong, 2020).

One debate in the conspiracy-theory research community is whether Trump has pushed more people into QAnon, or whether he just emboldened those who already believed. It's been a lesson in modern populism: a world leader ampli- fied once-obscure conspiracy theories, with each tweet and retweet strengthening their ideas and emboldening their supporters (Tollefson, 2021). Moreover, much of what is shared in QAnon groups on Facebook is a mix of pro-Trump political speech and pro-Trump political misinformation. Memes, videos and posts are often bigoted and disconnected from reality, but not all that different from the content that is shared in non-QAnon, proTrump Facebook groups (Wong, 2020a).

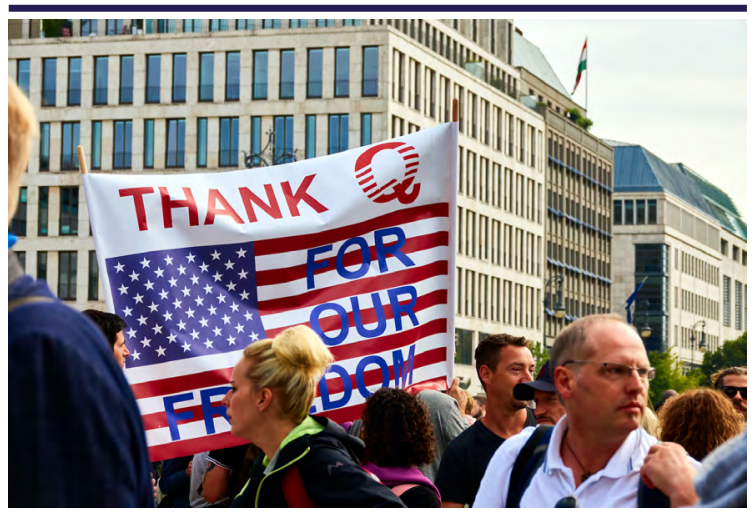

Demonstrators thank America and QAnon for the help and support in Berlin, Germany on August 29, 2020.

\section{Global QAnon As an American Export}

Conventional thinking about far-right extremism often frames it as a domestic problem within nation-states. But such groups and movements, including QAnon, are transnational, sharing ideas and tactics across borders (Miller-Idriss \& Koehler, 2021). QAnon has spread all over the world (MDI, 2020). Despite this, its growth in Europe and other parts of the world has gone mostly unnoticed. QAnon narratives are feeding on local contexts and attracting followers-both through popular local misinformation websites but also celebrities and politicians who are spreading the Q gospel. During the last two years, many new QAnon websites, pages, groups, and accounts appeared in the UK, France, Italy, and Germany, and quickly amassed large numbers of followers. They have also been shared within uniquely local groups, including pro-Yellow Vests groups in France and long-standing far-right conspiracy groups in Germany (Labbe et al., 2020). 
Although QAnon has spread to Europe, Latin America, and Australia-where it appears to be catching on among certain far-right movements (Wong, 2020)—every fourth QAnon tweet still originates in the US (Rupar \& Smedt, 2021; Farivar, 2020). Fuelled by worldwide anxiety over the pandemic, QAnon has gone global, with adherents popping up in at least 71 countries (Farivar, 2020). In August 2020, Argentino identified QAnon's presence in almost every country in Europe other than Estonia, Montenegro, and Albania. On August 22, 2020, as many as 200 street rallies were held across the US, Canada, and other countries under the inoffensive slogan of QAnon, "Save Our Children." QAnon narratives have also inspired a series of street demonstrations across the UK, which have been held in 17 cities and towns. Whilst most have been small, some have attracted hundreds of people, and QAnon is becoming an important component in the wider, conspiracy theory-driven, anti-lockdown movement (Lawrence \& Davis, 2020).

The earliest explicitly QAnon Facebook group was identified in the UK in June 2018, roughly eight months after the first Q drop. However, QAnon remained an exceedingly niche interest in the UK for the first two and a half years of its existence. This was to change with the onset of the pandemic. On August 22, 2020, several hundred protesters marched to Buckingham Palace, where a section of the crowd angrily chanted "paedophiles" outside the gates; a clip quickly went viral, receiving 3 million views in a matter of days. What many commentators missed in the moment was the QAnon iconography in the crowd (Lawrence \& Davis, 2020). QAnon is particularly well suited for adoption by right-wing reactionaries, who present themselves as chivalrous "protectors" of the nation and the family. However, QAnon has yet to spread wholesale into the British radical and far right, currently featuring as one of a myriad of fragmented concerns. But, its potent blend of anti-elitism and exploitation of deep-seated fears, combined with the growth of anti-COVID-19 conspiracy theories, means there is room for far-right converts and opportunists to take up its mantle and spread the theory further (Lawrence \& Davis, 2020).
Along with British influencer Martin Geddes, the European QAnon influencer who has had the greatest impact on the movement, both in the USA and internationally, is Janet Ossebaard, the Dutch producer of the viral documentary, "Fall of the Cabal." Having described the Pizzagate theory of mass-scale child abuse by Democratic politicians in the US, she then listed what she claimed were similar examples of elite Satanic abuse networks in the Netherlands, Belgium, Germany, Ireland, and the UK. This linking of QAnon themes to older European reference points is a key element to packaging QAnon for an international audience (Lawrence \& Davis, 2020).

In Germany, which has the world's second-highest number of QAnon believers (Wittig, 2020), QAnon has formed a distinct identity through its adoption by the Reichsburger movement, an existing far-right conspiracy theory that denies the legitimacy of the modern German state (Lawrence \& Davis, 2020). When about 40,000 demonstrators gathered in Berlin on August 22, 2020 to protest Germany's coronavirus lockdown restrictions, a small group broke off from this larger demonstration and approached the Reichstag. These far-right agitators attempted to storm the building. Inevitably, Germans saw shadows of this event in the January attack on the US Capitol (Miller-Idriss \& Koehler, 2021).

Nevertheless, perhaps the most vivid examples of the conflicting political interpretations of QAnon is visible in its manifestations in the former Yugoslav republics. Pro-QAnon groups can be found in Slovenia, Croatia, Bosnia-Herzegovina, Serbia, and Croatia. The largest QAnon Facebook group in the region is called QAnon Balkan which, as its name suggests, aims to unify the peoples of the region in support of the theory. Yet there are other Facebook groups which reflect national concerns rather than regional unity. Much of the discussion in the largest Serbia-specific QAnon group, for example, is fiercely nationalistic, with group members frequently expressing the desires to reassert Serbian sovereignty over Kosovo (Lawrence \& Davis, 2020). 


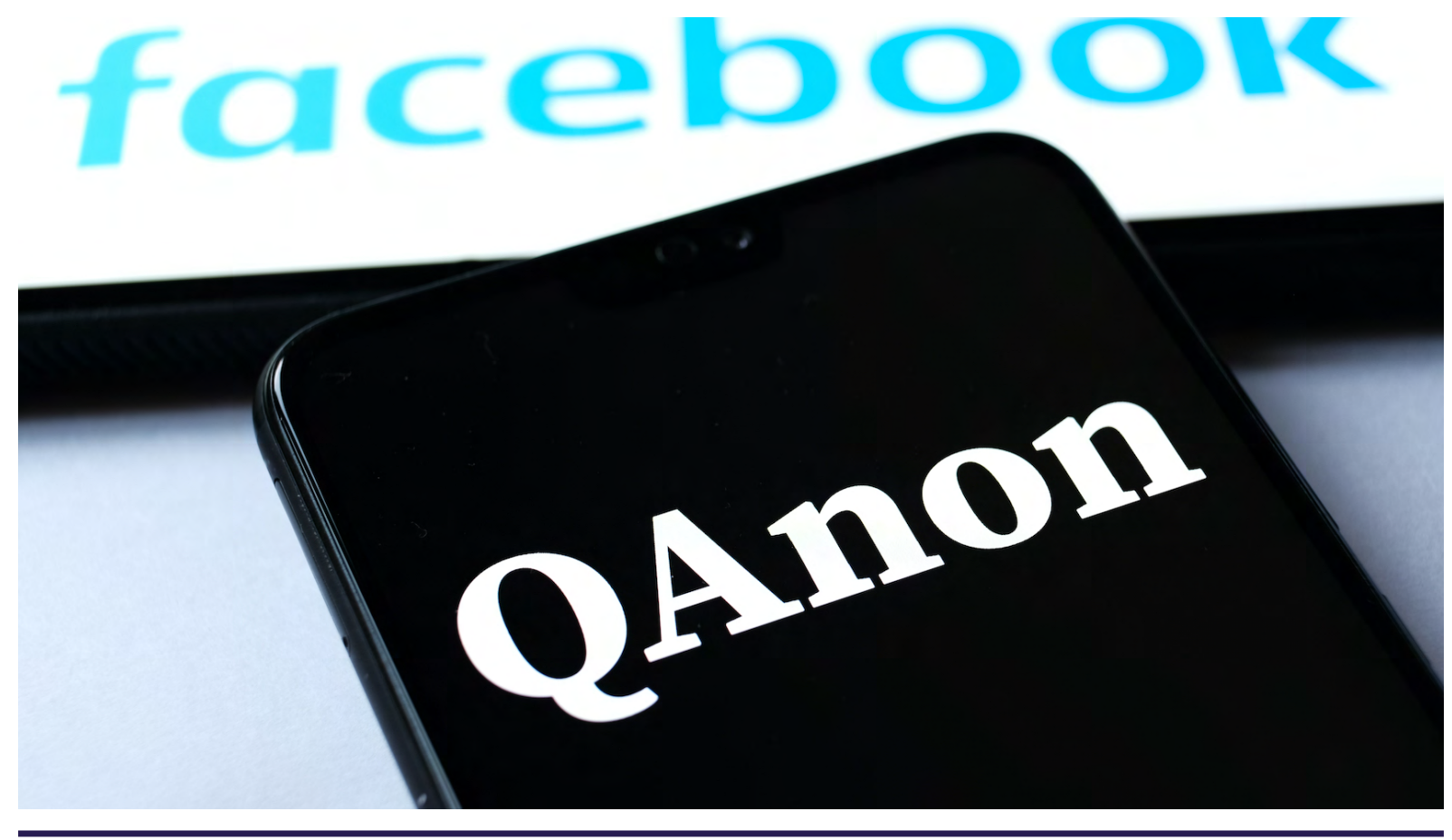

\section{QAnon: One of the Evil Products of So- cial Media}

As with ISIL, QAnon's ideology proliferates through easily-shareable digital content espousing grievances and injustices by "evil oppressors" (Giannotta, 2021). To perhaps a greater degree than any comparable movement, QAnon is a product of the social media era (Lawrence \& Davis, 2020) which created a perfect storm for it to spread (Jankowicz, 2021). However, without the anonymity provided by 4Chan and 8Chan, Q could not have kept up the charade of their assumed identity, nor could they have found a more receptive audience than the users of those platforms. Host to a legion of bored, alienated, and predominantly far-right users, the / $\mathrm{pol} /$ forum of 4chan was almost uniquely suited to birth an ideology that conspiracy theories, a promise of violent retribution against a liberal elite and, importantly, the encouragement of the audience to participate by conducting "research" of their own. Q's reach would have remained fringe, however, if it was limited to 4chan and 8chan (Lawrence \& Davis, 2020).

It was QAnon's spread onto the main- stream social media platforms-and from there onto the streets-that made this phenomenon into a global concern (Lawrence \& Davis, 2020). Social media platforms aided and abetted QAnon growth by driving vulnerable audiences to their content. For instance, Facebook was not merely providing a platform to QAnon groups; its powerful algorithms are actively recommending them to users. Facebook's own internal research in 2016 found that 64 percent of all extremist group "joins" are due to their recommendation tools (Horwitz \& Seetharaman, 2020). The digital architecture of Facebook groups is particularly well-suited to QAnon's collaborative construction of an alternative body of knowledge. The platform has created a ready-made digital pathway from public pages to public groups to private groups and, finally, secret groups that mirrors the process of "falling down the rabbit hole or taking the red pill" (Wong, 2020a). Recommendation algorithms on platforms prioritize engagement over truth, meaning that a search for natural health remedies, for instance, could lead users, in only a few clicks, to far more dangerous content (Jankowicz, 2021).

On the other hand, QAnon followers, some of whom spent 6 hour per day poring over Q's messages for clues to the conspiracy puzzle (Brooks et al., 2020), have used a wide range of online tactics 
to achieve virality and garner mainstream media coverage, including making "documentaries" full of misinformation, hijacking trending hashtags with QAnon messaging, showing up at rallies with $Q$ signs, or running for elected office. A very potent iteration of this tactic emerged in summer 2020 with the \#SaveTheChildren or \#SaveOurChildren campaign (Wong, 2020).

The hashtags, which had previously been used by anti-child-trafficking NGOs, has been flooded with emotive content by QAnon adherents hinting at the broader QAnon narrative. Hundreds of real-life "Save Our Children" protests have been organized on Facebook in communities across the US (and around the world). These small rallies are in turn driving local news coverage by outlets who don't realize that by publishing news designed to "raise awareness" about child trafficking, they are encouraging their readers or viewers to head to the internet, where a search for "save our children" could send them straight down the QAnon rabbit hole (Wong, 2020).

Even prior to the explosion of interest in conspiracy theories as the pandemic struck, QAnon had become a visible and viral presence online. Prominent promoters of the theory had gathered hundreds of thousands of followers on Twitter and YouTube, while QAnon Facebook groups had grown to tens of thousands of members (Lawrence \& Davis, 2020). Most of the QAnon profiles tap into the same sources of information: Trump tweets, YouTube disinformation videos, and each other's tweets. It forms a mutually reinforcing confirmation bias-the tendency to search for, interpret, favour, and recall information that confirms prior beliefs or values (Rupar \& Smedt, 2021).

Since the movement's earliest days, YouTube has played an essential role in the dissemination of QAnon narratives. In fact, it has been the gateway by which it first spread into the mainstream. Just one week after the first 4chan posts by $\mathrm{Q}$, a YouTuber named Tracy Diaz produced a video summarising the emerging narrative from $\mathrm{Q}$, bringing it to the attention of the wider conspiracy theorist community for the first time. Over the next few years, a huge community of QAnon interpreters emerged on YouTube, developing vast audiences for videos in which they dissect Q's posts and analyse the news cycle through the lens of QAnon. A spate of documentaries that promoted aspects of the QAnon narrative, such as "Fall of the Cabal", "Out of Shadows," and "Plandemic" were also posted on YouTube. These videos received millions of views (Lawrence \& Davis, 2020) while YouTube and other social media companies faced pressure over whether they would be banning QAnon-related activity.

Eventually, in August 2020, Twitter removed a false claim about coronavirus death statistics that Trump had retweeted. And Facebook said that it would ban any pages, groups, and Instagram accounts representing QAnon (Vazquez, 2020).While Facebook has policies banning hate speech, incitement to violence, and other types of content that it considers undesirable on a family-and advertiser-friendly platform, QAnon does not fit neatly into any single category. The anticipated purge by Facebook never came. Instead, QAnon groups on Facebook have continued to grow at a considerable pace. With more than 3 million aggregate followers and members, the groups and pages play a critical role in disseminating Q's messages to a broader audience (Wong, 2020a).

While QAnon thrives on Facebook, another social media site took timely and decisive action against it. Nearly two years ago, Reddit carried out a site-wide purge of QAnon-and made it stick (Wong, 2020a). In the wake of the Capitol insurrection, Twitter banned Trump, disconnecting him from his nearly 89 million followers, and took down more than 70,000 accounts linked to disinformation about campaign fraud and conspiracy theories. Facebook and YouTube have also suspended Trump's accounts. These actions have stifled the online conversation. An entire section tied to QAnon on Twitter disappeared overnight (Tollefson, 2021).

From August to November 30, 2020, Facebook removed about 3,000 Pages, 9,800 groups, 420 events, 16,200 Facebook profiles, and 25,000 Instagram accounts for "violating its policy against QAnon." Since then, the company continued to 
enforce this policy. As of January 12, 2021, Facebook had removed about 3,300 Pages, 10,500 groups, 510 events, 18,300 Facebook profiles, and 27,300 Instagram accounts for "violating its policy against QAnon" (Facebook, 2021). Twitter also suspended 70,000 accounts that share QAnon content at scale (BBC, 2021). Social media platforms' crackdown on QAnon disrupted the movement's ability to spread radical messages, but it won't stop the group completely (Argentino, 2020).

Following the announcement that YouTube would remove "conspiracy theory content used to justify real-world violence," many of the most prominent QAnon channels were removed, including the X22 Report, PrayingMedic, and others. Many of those users had already set up backup channels on largely unmoderated video platforms such as BitChute, the owner of which has expressed support for conspiracy theories and welcomed its proponents onto their platform. Yet none of the alt-tech sites can begin to match the audience sizes that YouTube can offer, and as such this move represents a significant blow to both the channel owners and the movement as a whole (Lawrence \& Davis, 2020).

After having their content restricted, QAnon supporters abandoned the big platforms and migrated to 4chan, a more permissive message board. When 4chan's moderation teams started tempering incendiary comments, QAnon followers moved to a new platform, 8chan (now called 8kun). These conspiracy theorists can still communicate with one another through ordinary email or on encrypted channels such as Signal, Telegram, and WhatsApp (Fukuyama et al., 2021). Some groups changed their names, substituting "17" for "Q" (the 17th letter of the alphabet); others shared links to back-up accounts on alternative social media platforms with looser rules (Wong, 2020a; Jankowicz, 2021).

QAnon has further fragmented into communities on Telegram, Parler, MeWe and Gab. These alternative social media platforms are not as effective for promoting content or merchandise, which will impact grifters who were profiting from QAnon, as well as limit the reach of proselytizers. But the ban will push those already convinced by QAnon onto platforms where they will interact with more extreme content they may not have found on Facebook. This will radicalize some individuals more than they already are or will accelerate the process for others who may have already been on this path (Argentino, 2020).

Experts doubt the disciplinary measures will banish the movement. Banning QAnon followers from Facebook and Twitter would also reinforce their belief that they're engaged in an information war against media elites and others in the deep state (Farivar, 2020). A Textgain analysis of 50,000 QAnon tweets posted from December 2020 - January 2021 showed toxicity had almost doubled, including 750 tweets inciting political violence and 500 inciting violence against Jewish people (Rupar \& Smedt, 2021).

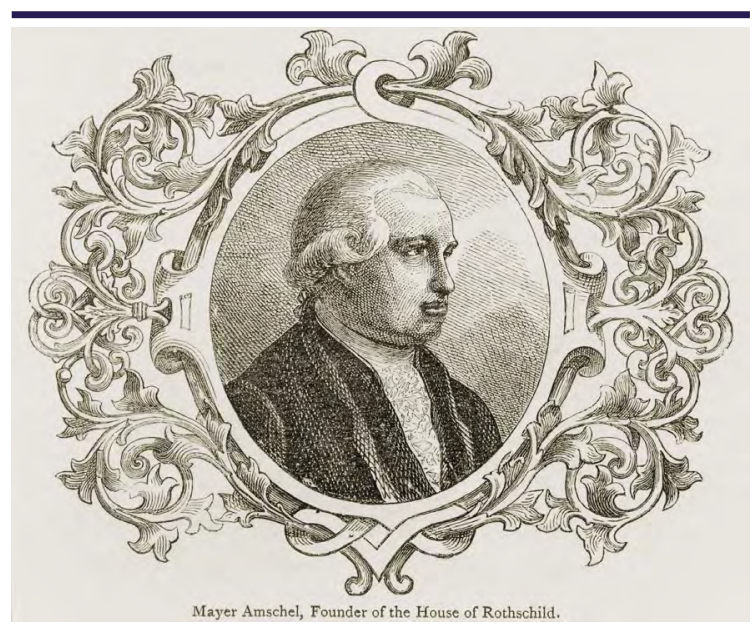

Meyer Amschel Rothschild (1744-1812), founder of the international banking family. Ca. 1790. Photo: Everett Collection

\section{QAnon Is Inherently Anti-Semitic}

A strong anti-Semitism has run through QAnon since the beginning-and is only growing more pronounced (Sales, 2020). QAnon draws together anti-Semitism, sexual excess, homophobia, and race-baiting in a modern-day moral panic (Evans, 2020). Whilst some followers may be conscious anti-Semites, others may be ignorantly regurgitating tropes they are unaware are racist; still others are simply 
turning a blind eye, denying charges of anti-Semitism as a mainstream media smear. Regardless, QAnon is promulgating an ancient form of prejudice and has the potential to radicalise converts towards Jew hatred (Lawrence \& Davis, 2020).

According to Gregory Stanton, who published a piece titled "QAnon is a Nazi cult, rebranded," QAnon is the latest version of "the conspiracy 'revealed' in the most influential anti-Jewish pamphlet of all time: Protocols of the Elders of Zion" (Sales, 2020), a fictional document first published in Russia in the early 1900s (Thomas, 2020). The fabricated document purports to expose a Jewish plot to control the world including infiltrating the media and political parties to brainwash and enslave populations and was used throughout the 20th century to justify anti-Semitism (Wong, 2020; Lawrence \& Davis, 2020). Examining past rhetoric targeting Jews reveals how such a discourse lubricates the machinery of violence-Hitler called the Protocols "immensely instructive" (Thomas, 2020).

Stanton (2020) also says QAnon's conspiracy theory is a rebranded version of the Protocols of the Elders of Zion. The cabal supposedly held the American Presidency under the Clintons and Obama, nearly took power again in 2016, and lurks in a "Deep State" financed by Jews, including George Soros, and in Jews who control the media. They want to disarm citizens and defund the police. They promote abortion, transgender rights, and homosexuality. They want open borders so brown illegal aliens can invade America and mongrelize the white race. According to Stanton, the world has seen QAnon before. It was called Nazism. "In QAnon, Nazism wants a comeback," he said.

Q has identified "puppet masters" at the centre of the international cabal: the Rothschild family and Soros. They have long been common targets for anti-Semitism, with the first smeared as sinister, sometimes supernatural global financiers for 200 years. Q has directly tapped into this toxic legacy, for example erroneously alleging that Rothschild has a controlling interest in every nation's central bank (Lawrence \& Davis, 2020). Both the Roth- schild family members and Soros were condemned, slandered, and blamed for supposedly trying to take control of the world and profiting from it because they are both wealthy and Jewish. QAnon supporters have continued to use this method of implicating them. In fact, this appears to be the most commonly used anti-Semitic dog whistle (MDI, 2020).

One general claim often used by QAnon supporters is that the Rothschild family and Soros are deeply involved in the "evil Project of billionaires" and are "exploiters of the pandemic" who own the COVID-19 "patents" that were supposedly used to manufacture the disease. In one video in particular, posted in French on Facebook, Soros is referred to as the "evil creature." Both the Rothschilds and Soros have also been condemned for their links to one another and to other large organizations. One particularly prominent example involves the World Health Organization (WHO), which is framed as a vehicle for global elites to exert control and ultimately perpetrate a global hoax supported and run by Bill Gates. QAnon supporters also frequently name the Rothschild family members and George Soros as founders and continuous funders of the WHO (MDI, 2020).

QAnon also has its roots in much older anti-Semitic conspiracy theories centring on the vulnerability of children. These are neither new nor distinctly American. The QAnon conspiracy about adrenochrome is a modern remix of the age-old anti-Semitic blood libel (Wong, 2020). In the Middle Ages, this was driven by a fear of Jewish magicians kidnapping and stabbing Christian children for evil rituals. The blood produced from these rites was rumoured to be ritually consumed as drink or mixed into matzo. It was a demonic fantasy and not based in any reality. It is noteworthy that QAnon claims about child abduction and blood consumption are linked to prominent Jewish figures (Thomas, 2020). "Hurting children is one of the worst things you can say someone is doing. It's an easy way to demonize your enemy," says Kathryn Olmsted, a professor of history at the University of California-Davis (Breland, 2019).

Some of QAnon's supporters are surely 
aware that they are targeting Jews. But, according to Sales (2020), the ideas of harvesting children's blood and controlling the world through a secret cabal are anti-Semitic, even if the growing numbers of QAnon adherents don't realize it or don't directly refer to Jews. These ideas are so old and established that they function as codes for anti-Semitism and obviate the need to mention Jews directly. These ideas act as dog whistles for neo-Nazis and other anti-Semites; they have the effect of propagating anti-Semitism regardless of their original intent (Sales, 2020).

Many of those within the QAnon movement have utilised this anti-Semitic dog whistling. In other words, QAnon supporters are repeatedly referencing certain people, terms, and narratives that may appear vague and harmless without context, but which actually signal a more insidious form of hate speech against all Jewish people. Specifically, dog whistling is being used as a tactic within the QAnon movement to denounce prominent Jewish public figures and global Jewry in ways that are all too familiar. Jews are being implicated in the spread and creation of Covid-19, as they have been blamed for many diseases throughout history (MDI, 2020). 




Anti-Mask Rally at the Ohio Statehouse - Boogaloo Boy infiltrates the counter-protest in Columbus, Ohio/ US on July 18. 2020. Photo: Dan Fleckner.

\section{CONCLUSION}

\section{Why Does QAnon Matter?}

First of all, there is a threat of violence. For those who truly believe that powerful figures are holding children hostage in order to exploit them sexually or for their blood, taking action to stop the abuse can seem like a moral imperative. While most QAnon followers will not engage in violence, many already have-or have attempted towhich is why the FBI has identified the movement as a potential domestic terror threat (Wong, 2020). The FBI has already described "conspiracy theory-driven domestic extremists," as a growing threat. It lists a number of arrests, including some that haven't been publicized, related to violent incidents motivated by fringe beliefs. An FBI document specifically mentions QAnon (Winter, 2019).

The FBI acknowledges that conspiracy theory-driven violence is not new-but also says it's gotten worse with advances in technology com- bined with an increasingly partisan political landscape. "The advent of the Internet and social media has enabled promoters of conspiracy theories to produce and share greater volumes of material via online platforms that larger audiences of consumers can quickly and easily access," the document says (Winter, 2019). Indeed, there have been numerous incidents of real-world violence linked to QAnon, and in May 2019, the FBI identified QAnon as a potential domestic terrorism threat in an intelligence bulletin. The bulletin stated the online narratives were determining the targets of harassment and violence for the small subset of individuals who crossed over into real-world action (Wong, 2020a)which can have serious consequences for the targets (Wong, 2020).

What's more, extremist groups like QAnon endanger democracy primarily when they leave the periphery of the Internet and enter the mainstream. This happens when their voices are either picked up by the media or amplified by a platform (Fukuyama et al., 2021). From the point of view of someone who believes the QAnon conspiracy theory that the Democratic Party elite are behind a vast paedophile ring threatening innocent children, perhaps January 6th really did seem to be an act of patriotism. Samuel Johnson famously claimed that "patriotism is the last refuge of the scoundrel," but as Zacek (2021) underlines and as is so often true, the reality is undoubtedly far more complex. 


\section{REFERENCES}

- (2020). "More than 1 in 3 Americans believe a 'deep state' is working to undermine Trump." Ipsos. December 30, 2020. https://www.ipsos.com/sites/default/files/ct/news/documents/2020-12/topline_npr_misinformation_poll_123020.pdf (accessed on February 23, 2021).

- (2020). QAnon and The Growing Conspiracy Theory Trend On Social Media. Media Diversity Institute (MDI). June 2020. https://www.media-diversity.org/wp-content/uploads/2020/07/QAnonFinalReport.pdf(accessed on February 28, 2021).

- (2021). "Twitter suspends 70,000 accounts linked to QAnon." BBC. January 12, 2021. https://www.bbc.com/news/technology-55638558 (accessed on February 28, 2021).

- (2021). "An Update to How We Address Movements and Organizations Tied to Violence." Facebook. January 19, 2021. https://about.fb.com/news/2020/08/addressing-movements-and-organizations-tied-to-violence/ (accessed on February 27, 2021).

— (2021). "Welcome to Church of All Worlds." caw.com. https://caw.org

Argentino, Marc-André. (2020). "Facebook, YouTube moves against QAnon are only a first step in the battle against dangerous conspiracy theories." The Conversations. October 15, 2020. https://theconversation.com/facebook-youtube-moves-against-qanon-are-onlya-first-step-in-the-battle-against-dangerous-conspiracy-theories-147883 (accessed on February 27,2021$)$.

Argentino, Marc-André. (2020a). "In the Name of the Father, Son, and Q: Why It's Important to See QAnon as a 'Hyper-Real' Religion." Religion Dispatches. May 28, 2020. https:// religiondispatches.org/in-the-name-of-the-father-son-and-q-why-its-important-to-see-qanon-as-a-hyper-real-religion/ (accessed on March 3, 2021).

Argentino, Marc-André. (2020b). "The Church of QAnon: Will conspiracy theories form the basis of a new religious movement?" The Conversations. May 18, 2020. https://theconversation.com/the-church-of-qanon-will-conspiracy-theories-form-the-basis-of-a-new-religiousmovement-137859 (accessed on February 27, 2021).

Argentino, Marc-André. (2020c). "QAnon conspiracy theory followers step out of the shadows and may be headed to Congress." The Conversations. July 8, 2020. https://theconversation.com/qanon-conspiracy-theory-followers-step-out-of-the-shadows-and-may-be-headed-to-congress-141581 (accessed on February 27, 2021).

Argentino, Marc-André. (2021). "QAnon and the storm of the U.S. Capitol: The offline effect of online conspiracy theories." The Conversations. January 7, 2021 https://theconversation. com/qanon-and-the-storm-of-the-u-s-capitol-the-offline-effect-of-online-conspiracy-theories-152815 (accessed on February 27, 2021).

Aubrey, Sophie. (2020). "'Playing with fire': The curious marriage of QAnon and wellness." Brisbane Times. September 27, 2020. https://www.brisbanetimes.com.au/lifestyle/healthand-wellness/playing-with-fire-the-curious-marriage-of-qanon-and-wellness-20200924p55yu7.html (accessed on February 27, 2021).

Beckett, Lois. (2020). "QAnon: a timeline of violence linked to the conspiracy theory." The Guardian. October 15, 2020. https://www.theguardian.com/us-news/2020/oct/15/qanon-violence-crimes-timeline (accessed on February 23, 2021).

Beene, S., \& Greer, K. (2021). "A call to action for librarians: Countering conspiracy theories 
in the age of QAnon." The Journal of Academic Librarianship. 47(1). https://doi.org/10.1016/j. acalib.2020.102292

Bergmann, Eirikur Einarsson. (2018). Conspiracy and Populism. New York: Palgrave Macmillan.

Binder, Matt. (2018). "Why Some Baby Boomers Are Eating Up the QAnon Conspiracy." Mashable. August 7, 2018. https://mashable.com/article/qanon-conspiracy-baby-boomers-4chan/ (accessed on March 2, 2021).

Bodner, J. (2021). Covid-19 conspiracy theories: QAnon, 5G, the New World Order and other viral ideas. McFarland \& Company, Inc., Publishers.

Bracewell, Lorna. (2021). "Gender, Populism, and the QAnon Conspiracy Movement." Frontiers in Sociology. January 21, 2021. 5. https://doi.org/10.3389/fsoc.2020.615727

Breland, Ali. (2019). "Why Are Right-Wing Conspiracies so Obsessed With Pedophilia?" Mother Jones. July-August 2019. https://www.motherjones.com/politics/2019/07/why-areright-wing-conspiracies-so-obsessed-with-pedophilia/ (accessed on February 25, 2021).

Breland, A. (2020). "The Summer QAnon Went mainstream." Mother Jones. August 2020. https://sci-hub.se/ https://www.motherjones.com/politics/2020/08/qanon-mainstream/ (accessed on March 2, 2021).

Brooks, A.; LaFrance, A.; Uscinski, J. E. \& Lytvynenko, J. (2020). "QAnon: A look inside the online conspiracy." WBUR OnPoint Radio. August 4, 2020. https://www.wbur.org/onpoint/2020/08/04/qanon-what-to-know-online-conspiracy (accessed on March 2, 2021).

Brotherton, Robert. (2013). "Towards a definition of 'conspiracy theory'." The British Psychology Society's quarterly magazine special issue: The psychology of conspiracy theories. Vol. 88. p. 56.

Brotherton, Robert. (2016). Suspicious minds: Why we believe conspiracy theories. Bloomsbury Sigma.

Brunvand, Jan Harold. (2001). Encyclopedia of Urban Legends. New York: Norton Paperbacks.

Butler, Kiera. (2020). "The Terrifying Story of How QAnon Infiltrated Moms' Groups." Mother Jones. September 23, 2020. https://www.motherjones.com/politics/2020/09/the-terrifying-story-of-how-qanon-infiltrated-moms-groups/ (accessed on February 25, 2021).

Butter, M. (2020). Routledge handbook of conspiracy theories. Conspiracy theories. Routledge.

Cohn, N. (1977). Europe's inner demons: An enquiry inspired by the great witch-hunt. New York, NY: New American Library.

Colarossi, Natalie. (2021). "White Evangelicals Are More Likely to Believe in QAnon Than Any Other Faith Group, Poll Finds." Newsweek. February 2, 2021. https://www.newsweek. com/white-evangelicals-are-more-likely-believe-qanon-any-other-faith-group-pollfinds-1568734 (accessed February 25, 2021).

Crokin, Liz. (2020). "Coronavirus Cover for Mass Arrests? Part II." YouTube. March 17, 2020. https://youtu.be/mSHqb9ctRGk

Evans, Jennifer. (2020). "Folk devils and fear: QAnon feeds into a culture of moral panic." The Conversations. October 25, 2020. 
https://theconversation.com/folk-devils-and-fear-qanon-feeds-into-a-culture-of-moralpanic-148606 (accessed on March 1, 2021).

Evans, Jules. (2021). "A Closer Look at the 'QAnon Shaman' Leading the Mob." Gen Medium. January 7, 2021. https://gen.medium.com/the-q-shaman-conspirituality-goes-rioting-on-capitol-hill-24bac5fc50e6 (accessed on March 10, 2021).

Farivar, Masood. (2020). "How the QAnon Conspiracy Theory Went Global." VOA. August 15, 2020. https://www.voanews.com/usa/how-qanon-conspiracy-theory-went-global (accessed on February 27, 2021).

Flora, L. (2020). 'I love you my beautiful \#QAnon': when lifestyle influencers also peddle conspiracy theories." Glossy. June 24, 2020. https://sci-hub.se/https://www.glossy.co/beauty/i-love-you-my-beautiful-qanon-when-lifestyle-influencers-also-peddle-conspiracy-theories/ (accessed on March 2, 2021).

Fukuyama, Francis; Richman, Barak \& Goel, Ashish. (2021). "How to Save Democracy From Technology." Foreign Affairs. January/February 2021. https://www.foreignaffairs.com/articles/united-states/2020-11-24/fukuyama-how-save-democracy-technology (accessed on February 23, 2021).

Fukuyama, Francis. (2021). "Rotten to the Core?" Foreign Affairs. January 18, 2021. https:// www.foreignaffairs.com/articles/united-states/2021-01-18/rotten-core (accessed on February 23, 2021).

Giannotta, Brent. (2021). "What I learned about Islamic State applies to QAnon too." Los Angeles Times. February 24, 2021. https://www.latimes.com/opinion/story/2021-02-24/whati-learned-about-islamic-state-applies-to-qanon-too (accessed on February 25, 2021).

Gillespie, Eden. (2020). 'Pastel QAnon': The Female Lifestyle Bloggers and Influencers Spreading Conspiracy Theories Through Instegram." The Feed. September 9, 2020. https:// www.sbs.com.au/news/the-feed/pastel-ganon-the-female-lifestyle-bloggers-and-influencers-spreading-conspiracy-theories-through-instagram (accessed on February 27, 2021).

Gingeras, Ryan. (2019). "How the Deep State Came to America: A History." War on the Rocks. February 4, 2019. https://warontherocks.com/2019/02/how-the-deep-state-came-toamerica-a-historyl (accessed on March 2, 2021).

Goldgeier, James \& Jentleson, Bruce W. (2021). "The United States Needs a Democracy Summit at Home." Foreign Affairs. January 9, 2021. https://www.foreignaffairs.com/articles/ united-states/2021-01-09/united-states-needs-democracy-summit-home (accessed on February 23, 2021).

Greenwood, Sue. (2020). "How QAnon conspiracy theory memes are spreading on Facebook in the UK." The Conversation. September 25, 2020. https://theconversation.com/howganon-conspiracy-theory-memes-are-spreading-on-facebook-in-the-uk-145820 (accessed on February 26, 2021).

Hafford, Michael. (2017). "Heaven's Gate 20 Years Later: 10 Things You Didn't Know." Rolling Stone. March 24, 2017. https://www.rollingstone.com/feature/heavens-gate-20-years-later10-things-you-didnt-know-114563/ (accessed on February 27, 2021).

Halpern, D., Valenzuela, S., Katz, J., \& Miranda, J. P. (2019). "From Belief in Conspiracy Theories to Trust in Others: Which Factors Influence Exposure, Believing and Sharing Fake News." Lecture Notes in Computer Science. 217-232. doi:10.1007/978-3-030-21902-4_16

Horwitz, Jeff \& Seetharaman, Deepa. (2020). "Facebook Executives Shut Down Efforts to Make the Site Less Divisive." The Wall Street Journal. May 26, 2020 
https://www.wsj.com/articles/facebook-knows-it-encourages-division-top-executives-nixed-solutions-11590507499 (accessed on February 23, 2021).

Jankowicz, Nina (2021). "The Day the Internet Came for Them." Foreign Affairs. January 12, 2021. https:/www.foreignaffairs.com/articles/united-states/2021-01-12/day-internet-camethem (accessed on February 23, 2021).

Kaplan, Alex. (2020). "Here are the QAnon supporters running for Congress in 2020." Media Matters. September 11, 2020. https://www.mediamatters.org/qanon-conspiracy-theory/ here-are-ganon-supporters-running-congress-2020 (accessed on February 23, 2021).

Kaplan, Alex. (2021). "Trump has repeatedly amplified QAnon Twitter accounts. The FBI has linked the conspiracy theory to domestic terror." Media Matters. January 11, 2021. https:// www.mediamatters.org/twitter/fbi-calls-qanon-domestic-terror-threat-trump-has-amplified-qanon-supporters-twitter-more-20 (accessed on February 27, 2021).

Kelly, A. (2020). "Mothers for QAnon." New York Times. September 10, 2020. https://sci-hub. se/https://www.nytimes.com/2020/09/10/opinion/qanon-women-conspiracy.html (accessed on March 2, 2021)

Kline, Jim. (2017). "C. G. Jung and Norman Cohn Explain Pizzagate: The Archetypal Dimension of a Conspiracy Theory." Psychological Perspectives. 60(2), 186-195. doi:10.1080/0033292 5.2017 .1314699

Labbe, Chine; Padovese, Virginia; Richter, Marie \& Harling, Anna-Sophie. (2020). "Special Report: QAnon in Europe - QAnon's Deep State conspiracies spread to Europe." NewsGuard. https://www.newsguardtech.com/special-report-qanon/ (accessed on February 23, 2021).

LaFrance, Adrienne. (2020). "The Prophecies of Q." The Atlantic. June 2020. https://www. theatlantic.com/magazine/archive/2020/06/qanon-nothing-can-stop-what-is-coming/610567/?utm_source=newsletter\&utm_medium=email\&utm_campaign=atlantic-daily-newsletter\&utm_content=20200514\&silverid-ref=MzEWMTU3MzM4ODg2SO (accessed on February 27, 2021).

Lavelle. Daniel. (2020). 'You have to face the darkness within you': meet the real-life Jedi knights." The Guardian. February 11, 2020. https://www.theguardian.com/world/2020/feb/11/ you-have-to-face-the-darkness-within-you-meet-the-real-life-jedi-knights (accessed on February 27, 2021).

Lawrence, David \& Davis, Gregory. (2020). "QAnon in the UK - The Growth of a Movement." Hope Not Hate Charitable Trust. October 2020. https://www.hopenothate.org.uk/wp-content/uploads/2020/10/qanon-report-2020-10-FINAL.pdf (accessed on February 25, 2021).

Liptak, Kevin. (2020). "Trump embraces QAnon conspiracy because 'they like me'." CNN. August 20, 2020. https://edition.cnn.com/2020/08/19/politics/donald-trump-qanon/index. html (accessed on February 21, 2021).

Manjoo, Farhad. (2020). "I spoke to a scholar of conspiracy theories and I'm scared for us." The New York Times. October 21, 2020. https://www.nytimes.com/2020/10/21/opinion/q-anon-conspiracy.html (accessed on March 2, 2021).

Mantyla, Kyle. (2020). "Liz Crokin Claims Celebrities are Getting Coronavirus from Tainted 'Adrenochrome Supply'." Right Wing Watch. March 18, 2020. https://www.rightwingwatch. org/post/liz-crokin-claims-celebrities-are-getting-coronavirus-from-tainted-adrenochrome-supply/ (accessed on March 2, 2021).

Martineau, Paris. (2017). "The Storm Is the New Pizzagate-Only Worse." Intelligencer. 
December 19, 2017. https://nymag.com/intelligencer/2017/12/qanon-4chan-the-storm-conspiracy-explained.html (accessed on March 2, 2021).

Miller-Idriss, Cynthia \& Koehler, Daniel. (2021). "A Plan to Beat Back the Far Right." Foreign Affairs. February 3, 2021. https://www.foreignaffairs.com/articles/united-states/2021-02-03/ plan-beat-back-far-right (accessed on February 23, 2021).

Mitchell, A., Jurkowitz, M., Oliphant, J. B., \& Shearer, E. (2020). "Most Americans who have heard of QAnon conspiracy theories say they are bad for the country and that Trump seems to support people who promote them." Pew Research Center, Journalism and Media. September 16, 2020. https://www.journalism.org/2020/09/16/most-americans-whohave-heard-of-qanon-conspiracy-theories-say-they-are-bad-for-the-country-and-thattrump-seems-to-support-people-who-promote-them/ (accessed on March 2, 2021).

Mogelson, Luke. (2021). "Among the Insurrectionists." The New Yorker. January 15, 2021. https://www.newyorker.com/magazine/2021/01/25/among-the-insurrectionists (accessed on February 25, 2021).

Murphy, Paul P. (2020). "Born on the dark fringes of the internet, QAnon is now infiltrating mainstream American life and politics." CNN. July 3, 2020. https://edition.cnn. com/2020/07/03/us/what-is-qanon-trnd/index.html (accessed on February 21, 2021).

O'Donnell, S. Jonathon. (2020). "Demons of the deep state: how evangelicals and conspiracy theories combine in Trump's America." The Conversation. September 14, 2020. https:// theconversation.com/demons-of-the-deep-state-how-evangelicals-and-conspiracy-theories-combine-in-trumps-america-144898 (accessed on February 26, 2021).

Phillips, Whitney \& Milner, Ryan M. (2020). You Are Here: Field Guide for Navigating Polarized Speech, Conspiracy Theories, and Our Polluted Media Landscape. Cambridge, MA: MIT Press.

Roberts, J. (2013). "The biggest secret: Do reptilian-human hybrids run our world." Collective Evolution. October 17, 2013. http://www.collective-evolution.com/2013/10/17/david-ickes-theory-of-the-reptilian-human-hybrid-apocalypse/

Rosenberg, Alyssa. (2019). "I Understand the Temptation to Dismiss QAnon. Here's Why We Can't." Washington Post.August 7, 2019. https://www.washingtonpost.com/opinions/2019/08/07/qanon-isnt-just-conspiracy-theory-its-highly-effective-game/ (accessed on March 2, 2021).

Rothschild, Mike. (2021). "Did an IP address accidentally reveal QAnon's identity?" The Daily Dot. January 27, 2021. https://www.dailydot.com/debug/who-is-qanon-jim-watkins-rumors/ (accessed on March 2, 2021).

Rupar, Verica \& Smedt, Tom De. (2021). "Trump's time is up, but his Twitter legacy lives on in the global spread of QAnon conspiracy theories." The Conversations. January 19, 2021. https://theconversation.com/trumps-time-is-up-but-his-twitter-legacy-lives-on-in-theglobal-spread-of-qanon-conspiracy-theories-153298 (accessed on February 28, 2021).

Sales, Ben. (2020). "QAnon is an old form of antisemitism in a new package, experts say." The Jerusalem Post.September 19, 2020. https://www.jpost.com/diaspora/antisemitism/qanon-is-an-old-form-of-antisemitism-in-a-new-package-experts-say-642852 (accessed on March 1, 2021).

Scott, Peter Dale. (1996). Deep Politics and the Death of JFK. Berkeley: University of California Press.

Seitz, Amanda. \& Swenson, Ali. (2020). "Baseless Wayfair child-trafficking theory spreads 
online." AP News. July 16, 2020.https://sci-hub.se/https://apnews.com/article/9d54570ebba5e406667c38cb29522ec6 (accessed on March 2, 2021).

Smedt, Tom De \& Rupar, Verica. (2020). QAnon 2: Spreading Conspiracy Theories on Twitter. Media Diversity Institute. December 2020. https://staticl.squarespace.com/static/5ee500d316a2470c370596d3/t/5fe3207446bf310e1611a53b/160872 0522110/QAnon+Report+2.pdf (accessed on February 28, 2021).

Sommer, Will. (2018). "QAnon, the Pro-Trump Conspiracy Theorists, Now Believe JFK Jr. Faked His Death to Become Their Leader." The Daily Beast. August 02, 2018. https://www. thedailybeast.com/qanon-the-pro-trump-conspiracy-theory-now-believes-jfk-jr-faked-hisdeath-to-become-its-leader (accessed on February 27, 2021).

Stanton, Gregory. (2020). "QAnon is a Nazi Cult, Rebranded". Just Security. September 9, 2020. https://www.justsecurity.org/72339/qanon-is-a-nazi-cult-rebranded/ (accessed on March 1, 2021).

Thomas, Paul. (2020). "How QAnon uses satanic rhetoric to set up a narrative of 'good vs. evil'." The Conversations.October 20, 2020. https://theconversation.com/how-qanon-usessatanic-rhetoric-to-set-up-a-narrative-of-good-vs-evil-146281 (accessed on March 3, 2021).

Thompson, Hunter S. (1972). Fear and Loathing in Las Vegas. New York: Random House.

Tiffany, Kaitlyn (2020). "The women making conspiracy theories beautiful." The Atlantic. August 18, 2020. https://www.theatlantic.com/technology/archive/2020/08/how-instagram-aesthetics-repackage-qanon/615364/ (accessed on February 24, 2021).

Tollefson, J. (2021). "Tracking QAnon: How Trump turned conspiracy-theory research upside down." Nature (London). 590 (7845), 192-193. https://doi.org/10.1038/d41586-021-00257-y (accessed on February 21, 2021).

Tuters, Marc. (2020). "How conspiracy theories spread online - it's not just down to algorithms." The Conversations.April 7, 2020. https://theconversation.com/how-conspiracytheories-spread-online-its-not-just-down-to-algorithms-133891 (accessed on February 26, 2021).

Uscinski, J. E. (2020). Conspiracy theories: A primer. Rowman \& Littlefield.

Uscinski, J. E., \& Parent, J. M. (2014). American conspiracy theories. Oxford University Press.

Vazquez, Maegan (2020). "Trump again refuses to denounce Qanon." CNN. October 16, 2020. https://edition.cnn.com/2020/10/15/politics/donald-trump-qanon-town-hall/index. html (accessed on February 21, 2021).

Winter, Jana. (2019). "Exclusive: FBI document warns conspiracy theories are a new domestic terrorism threat." Yahoo News. August 1, 2019. https://news.yahoo.com/fbi-documents-conspiracy-theories-terrorism-160000507.html (accessed on February 23, 2021).

Virgil. (2016). "The Deep State vs. Donald Trump." Breitbart. December 12, 2016. https:// www.breitbart.com/politics/2016/12/12/virgil-the-deep-state-vs-donald-trump/ (accessed on March 2, 2021).

Wittig, Peter. (2020). "Hope for the Future of American Leadership Dies Hard." Foreign Affairs. October 16, 2020. https://www.foreignaffairs.com/articles/europe/2020-10-16/hope-future-american-leadership-dies-hard (accessed on February 23, 2021).

Wong, Julia Carrie. (2018). "What is QAnon? Explaining the bizarre rightwing conspiracy theory." The Guardian. July 31, 2018. 
https://www.theguardian.com/technology/2018/jul/30/qanon-4chan-rightwing-conspiracy-theory-explained-trump (accessed on February 23, 2021).

Wong, Julia Carrie. (2020). "QAnon explained: the antisemitic conspiracy theory gaining traction around the World." The Guardian. August 25, 2020. https://www.theguardian.com/ us-news/2020/aug/25/qanon-conspiracy-theory-explained-trump-what-is (accessed on February 23, 2021).

Wong, Julia Carrie. (2020a). "Down the rabbit hole: how QAnon conspiracies thrive on Facebook." The Guardian. June 25, 2020. https://www.theguardian.com/technology/2020/jun/25/ ganon-facebook-conspiracy-theories-algorithm (accessed on February 23, 2021).

Zacek, Natalie. (2021). "'Patriots' in America: how fighting for your country has taken on new meaning for Trump supporters." The Conversation. February 17, 2021. https://theconversation.com/patriots-in-america-how-fighting-for-your-country-has-taken-on-newmeaning-for-trump-supporters-154859 (accessed on February 26, 2021).

Zadrozny, Brandy \& Collins, Ben. (2018). "How Three Conspiracy Theorists Took 'Q' and Sparked Qanon." ABC News. August 14, 2018. https://www.nbcnews.com/tech/tech-news/ how-three-conspiracy-theorists-took-q-sparked-qanon-n900531 (accessed on March 2, 2021). 


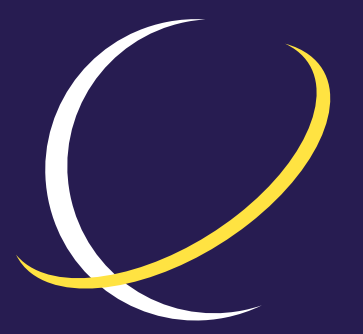

\section{ECPS \\ EUROPEAN CENTER for POPULISM STUDIES}

\section{ABOUT ECPS}

The European Center for Populism Studies (ECPS) is an independent, nonpartisan, nonprofit organization, based in Brussels, for research on and analysis of challenges posed by the resurgence of political populism. ECPS facilitates collaboration among networks of academic experts, practitioners, policymakers, media, and other stakeholders. ECPS offers a platform for the exchange of policy solutions on issues relating to rising populism and provides insights for policy-making and critical analysis to raise broader awareness and engagement through:

\section{Publications}

\section{Academic publications}

Policy reports

White papers

Commentaries

Podcasts and interviews with experts

Events, seminars, workshops, and conferences

\section{Research Programs}

Authoritarianism

Digital Populism

Economics

Environment \& Climate

Extremism \& Radicalisation

\section{Gender}

Human Rights

Foreign Policy

Leadership \& Persona

Migration

\section{ECPS Youth Program}

ECPS Academy 